المستخلص. تهدف الدر اسـة الحاليـة إلى اختبار فعاليـة المستخلصـات المائيـة لأوراق نباتـات الأكاسيا Eucalyptus gomphocephala واللفلة Acacia

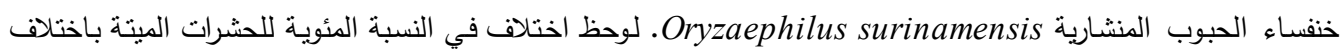
المستخلص والتزكيز المستخدم وفترة التعريض والطور المعالج. وتبين تفوق مستخلص الدفلة في قتل اليرقات والبالغات تلاه

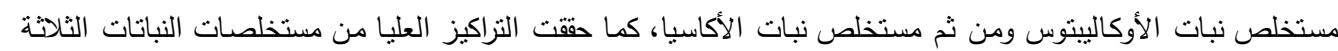
المختبرة أعلى نسبة مـوت في اليرقات والبالغـات، وسبَبت زيادة نسبية في طول عمر يرقات الطور الرابع مقارنـةً بالشـاهد. وتبين من الدراسة أن يرقات الطور الثاني والثالث كانت أكثر استجابة للتأثثر القاتل للمستخلصات النباتية من يرقات الطور الرابع وبالغات الحشرة المدروسة.

الكلمات المفتاحية: المستخلصات النباتية، التأثير الطارد، التأثير القاتل، الأطوار اليرقية، O.surinamensis. 
البـاحثين في هذا المجـال لإيجـاد بـدائل طبيعيـة آمنـة على صـحة الإنسـان والبيئة مـن أجـل مكافحـة حشـرات المخـازن

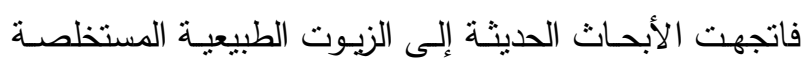
من النباتات، حيث نؤثر المركبات المشتقة من النباتات بعدة

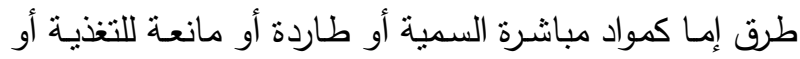

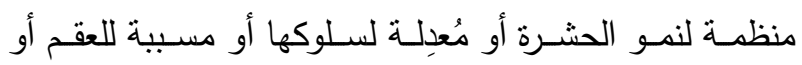

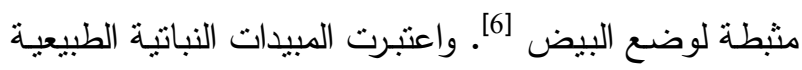
وسيلة أوليـة للتأثير في الحشـرات، ووسيلة أساسية لحمايـة الإنتاج الزراعي والبيئة من النلوث بالمبيدات.

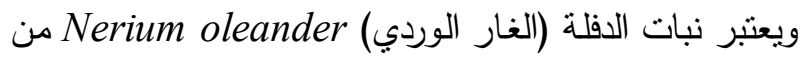
أكثر النباتات السامة التي تحتوي على مركبات سـامة تتوزع

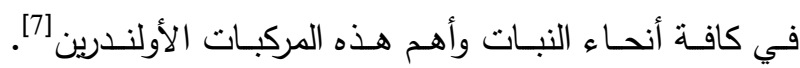

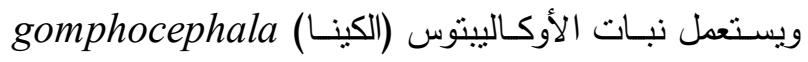
Eucalyptus

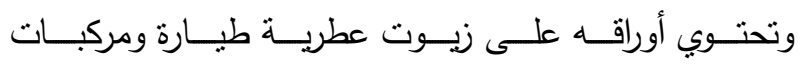

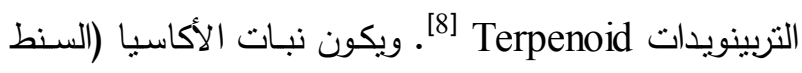
الأزرق) Acacia cyanophylla ذا تأثير طارد للحشرات

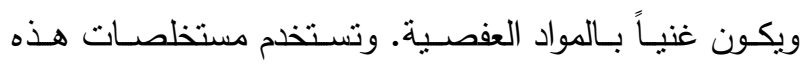
النباتات في صناعة المبيدات الحشرية. أهمية البحث:

نظـراً لصـعوبة مكافحـة حشـرات مخـازن الحبـوب بسبب وجودهـا مـع المـواد الغذائيـة، وبسـبـ مـا تسـبيه مـن أضــرار كبيـرة فـي المخـزون، وخطــورة اســتخدام المبيـدات الكيميائية المصنعة، كان لابد من البحث عن أساليب جديدة

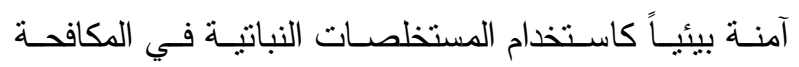
الحيويـة للآفـات الاقتصـادية. حيـث تتميـز المستخلصـات النباتيـة بسميتها المنخفضــة على الثدييات، وفعاليتها القويـة كمبيدات حشرية حيويـة واسعة الطيف، وانخفاض مخاطرها على الكائنـات غير المستهوفة، وكلفتهـا المنخفضـــة وتوفرهـا الطبيعي في البيئة، وسهولة استخدامها.

\section{1. المقدمة}

Oryzaephilus تعد خنفساء الحبوب المنشارية Surinamensis L,1758 الضـرر للحبـوب فـي المخـازن والصـوامع مسـببةً مشــاكل اقتصـادية خطيـرة، وتصـيب الحبـوب المخزونـة ومنتجاتهـا

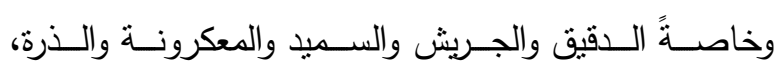

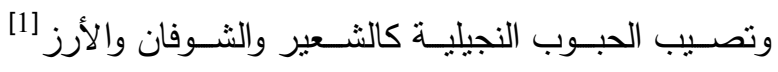
والبـذور الزيتيــة والتوابـل، وتعـيش أيضــأً على الثــوكولا

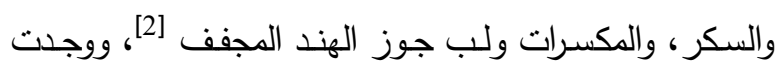

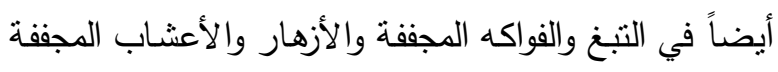

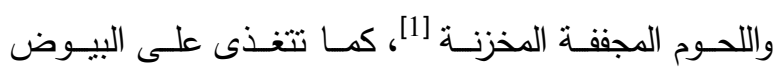
والحشرات المينة من فراشات الحبوب المخزونة [3]. التحول الشكلي عند حشرة O.surinamensis من النمط من ورات الكامل حيث تبـدأ دورة حياتهـا بمرحلة البيضـة ثم مرحلـة

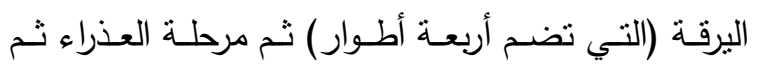
الحشرة الكاملة، ويستغرق زمن التطور من البيضـة حتى لئى

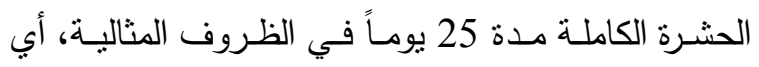
هناك أربع إلى خمس أجيـال في السنة، وتتحمل الحشـرة

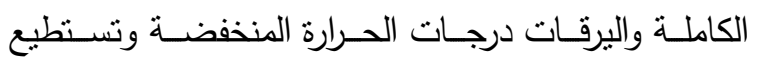
مقاومـة البرد مما يجعلها آفة دائمة، كما أنها طويلة العمر يمكنها العيش من سنتين إلى ثنلاث سنوات مسبيةً أضراراً بالغة في المخزون، لذلك أولت الدراسـات هذه الخنفسـاء

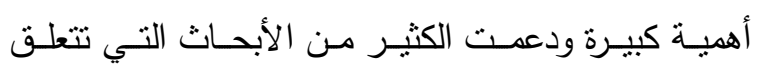

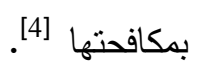

وتكمن صعوبة مكافحـة هذه الحشرات في وجودهـا مع المواد

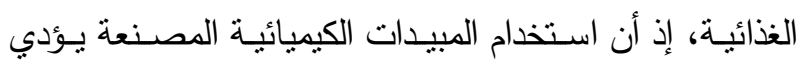

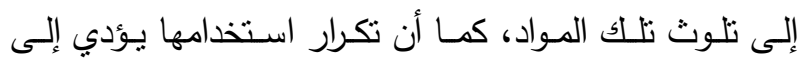
زيادة ظهور الآفات والسلالات المقاومة، وإلى حدوث خلل في

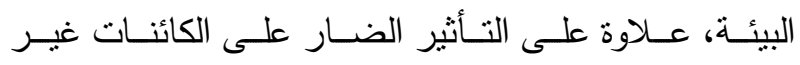

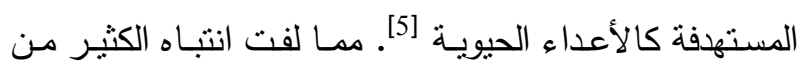




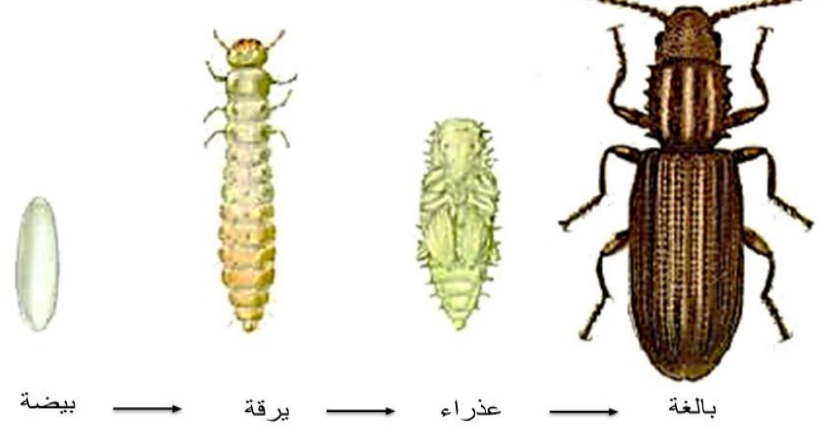

الثكل رقم (1)

دورة حياة خنفساء الحبوب المنثارية O.surinamensis

2-2-2 طريقة تحضير المستخلصات النباتية المائية:

تم جمع الأوراق النباتية من أشجار السنط الأزرق A gomphocephala cyanophylla الوردي N. oleander خـلا موسم إزهارهـا في الصيف من حرم جامعـة حلب، وتم غسلها بالمـاء، ثم جفقت في

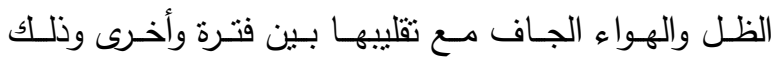
للحصول على وزن ثابت، وخزنت الأوراق الجافة في أوعية مناسبة وحفظت في مكان جـاف وبـارد. ثم تم طحن كميـة

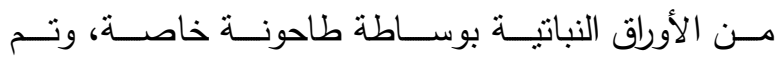

استخلاص المادة الفعالة وفق الخطوات التالية [11]؛

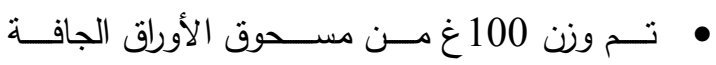
وإضافتها إلى ليتر من الماء المقطر في دورق سعة 2 ليتر ،

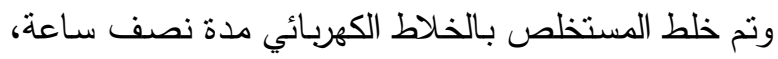
وترك المزيج منقوعاً مدة 2 ساعة. • ثم تم ترشيحه بورق ترشيح، ثم تثقيله بمثقلة تدور

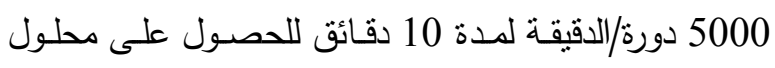
رائق من المستخلص. تــم تجفيــف الخلاصـــة بجهــاز المبخــر الــوار Rotary evaporator وتم تكثيفها مـن أجل تبخير المذيب المـائي حتى الحصسول

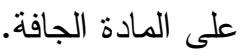

\section{الهذف من البحث}

1- دراسة التأثير الطارد لمستخلصات أوراق نباتات الأكاسيا E.gomphocephala والأوكالييتوس A. cyanophylla والدفلة N.oleander في بالغات خنفساء الحبوب المنشـارية .O.surinamensis 2- دراسـة التـأثير القاتل لتراكيز مختلفـة مـن مستخلصـات

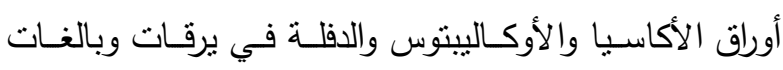
خنفساء الحبوب المنشارية O.surinamensis. 2 - مواد وطرق العمل 1-2 تهيئة مجموعات الحشرات :

جمعت العينات من مواد غذائية مصابة بالحشرات من الأسـواق التجاريـة والأفـران والمـؤن المنزليـة في مدينـة حلب خلال فترة تكاثر الحشرات في فصل الصيف. Silvanidae تم عـل خنـافس الحبـوب مـن فصـيلة وتم تعريفها في المختبر حتى مسنتوى النوع المطلوب بالاعتمـاد علـى المعـايير التصــنيفية المـأخوذة مــن فئن المفاتيح التصنيفية [9-10].

تمــت مزاوجـة الــكور والإنـاث بـأحواض بلاسـتيكية

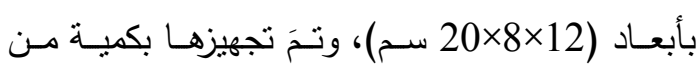
الطعام المكون من الحبوب والخميرة بنسبة 5\% وذللك في حاضنة بدرجة حرارة 30 م؛ ورطوبة 65\%.

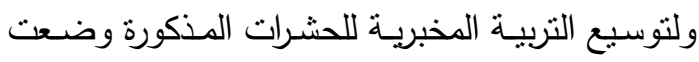

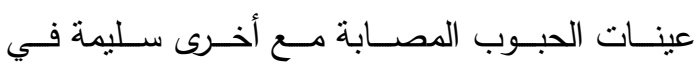
الحاضنة، ثم جمعت الخنـافس الفاقسـة ووضـعت في أوعية جديدة بداخلها حبوب سليمة.

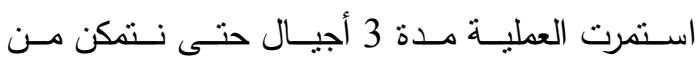
الحصول على أعداد وفيرة من الحشـرات تكفي لبده

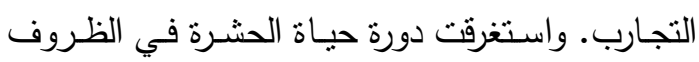
المخبرية مدة 30 يوماً (الشكل 1). 


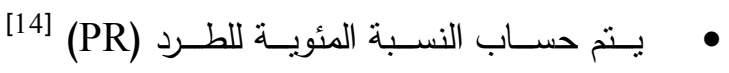
كالتالي:

$$
\mathrm{PR}=[(\mathrm{NC}-\mathrm{NT}) /(\mathrm{NC}+\mathrm{NT})]^{*} 100
$$

حيـث: (NC)عـد الحشـرات فـي المنـاطق الثــاهدة، و (NT) عــد الحشــرات فـــي المنـــاطق المعاملـــة

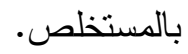
• تـم احتسـاب قيمـة الطـرد لكـل مسـتخلص نبـاني حسب قوة الطرد [15] وتصنيفها إلى خمس فئات (وتزداد قوة الطرد بازدياد رقم الفئة، وتكون الفئة الخامسـة الأشد طـرداً)

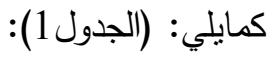
الجدول رقم (1) تصنيف قيم الطرد

\begin{tabular}{|c|c|}
\hline $0.1 \%>P R$ & الفئة 0 \\
\hline$[20 \%-0.1 \%]=\mathrm{PR}$ & الفئة 1 \\
\hline$\left[\begin{array}{ll}40 \% & -20.1 \%]=\mathrm{PR}\end{array}\right.$ & الفئة 2 \\
\hline$[60 \%-40.1 \%]=P R$ & الفئة 3 \\
\hline$[80 \%-\% 60.1 \%]=P R$ & الفئة 4 \\
\hline$[100 \%-80.1 \%]=P R$ & الفئة 5 \\
\hline
\end{tabular}

2-3-2-2 دراسـة التـأثير القاتـل للمستخلصـات النباتبـة فـي

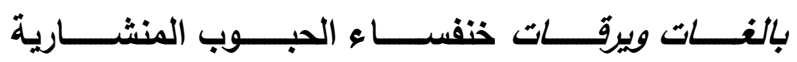
:O.surinamensis • تح ش ش غذاء الحشرات (المكون من 5غ من الدقيق و 0.25 غن الخميرة) بالتراكيز (3\% و 5\% و 7\% و 9 \% من المستخلصات النباتية الثناثة. •تم إدخـال 20 حشـرة مـن كل مـن الأطـوار اليرقيـة L2, L3, L4 (Larval stage) حشرة بالغة (Adult) A بعدر 14 يوماً إلى كل طبق بتري وبواقع ثناثة مكررات لكل تركيز وشاهد.

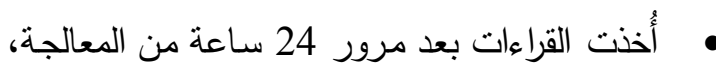

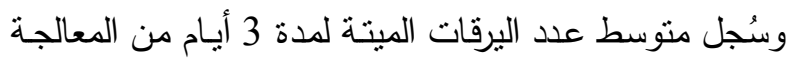

• تم حـل المـادة الجافـة بالمــاء المقطـر وتحضـير

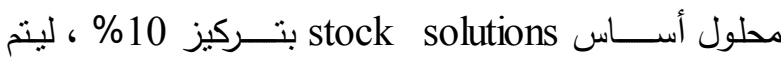
تحضير باقي التراكيز بدءاً منه وهي 3\% و 5\% و 7\% و 9\%، وحفظت المحاليل في البراد بدرجـة حرارة 4 مْ لحين وهين

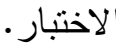
2-3-2 تصميم تجارب المكافحة الحيوية:

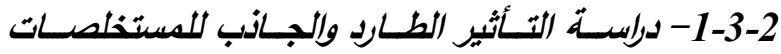
النباتبــة فـــي بالغــات خنفســـاء العبــوب المنشــارية $: O$.surinamensis

• تم تقيم الطـرد باسـتخدام طريقة تفضـيل المنطقـة Area preference method الاختبار من ورق ترشيح بقطر 9 سم، ثُص ورقة ترشيح في المنتصف. ويتم تطبيق (1 مل) من التراكيز الأربعـة لكل مستخلص في أحد نصفي ورقة الترشيح بالماصسة ويعامل

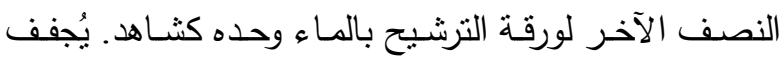

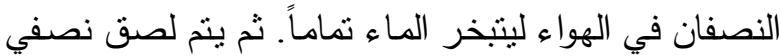
ورقة الترشيح معاً في كل طبق بنري.

تمَ إخال عشرة خنافس بالغة في مركز كل ورقة دائرية ثم تمت تغطية الطبق البتري، وكررت كل معاملة 3 مرات.

سـجل عــد الحشـرات الموجـودة علـى المنــاطق الثاهدة والمعاملة بعد (1/2 ساعة-2 ساعة-4 ساعات-24 سـاعة). ثم تم احتسـاب مؤشـر الطـرد (IR) مـن خـلال

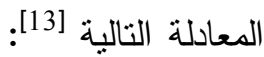

$$
\mathrm{IR}=2 \mathrm{G} / \mathrm{G}+\mathrm{P}
$$

حيث (G) المناطق المعاملة و(P) مناطق الثاهد. يصنف مؤشر الطرد كمايلي:

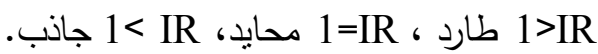
م قيمة IR أقل من 1 فالنبات طارد Repellency.

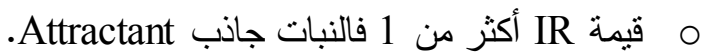
م قيمة IR تساوي 1 فالنبات محايد Neutral. 
التعريض و 93.3\% بعد 24 سـاعة مـن التعـريض، وبلغت أدنى نسبة مئويـة للطـرد عند التركيز 3\% لمستخلص هذا النبـات 66.6\% بعد نصف سـاعة من التعريض و63.6\%

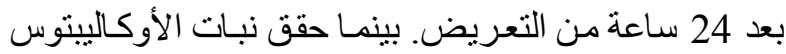
أعلى نسبة طرد عند التركيز \% 9 بلغت 70\% بعد نصـف ساعة من التعريض و83.3\% بعد 24 سـاعة من التعريض،

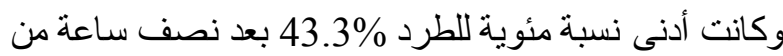
التعريض للتركيز \% 3 من مستخلص هذا النبات. أمسا نبات

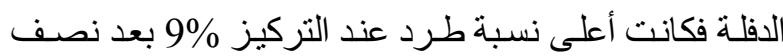
سـاعة مـن التعـريض\%\% 76.6و\% 86.6\% بعد 24 سـاعة مـن

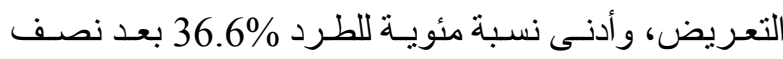
ساعة من التعريض للتركيز \% 3 من مستخلص هذا النبات

$$
\text { (الجدول رقم 2). }
$$

وعند حسـاب مؤشر الطرد وتقييم قوة الطرد تبين

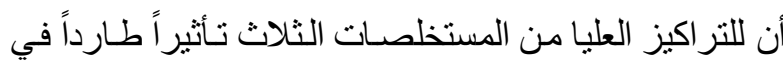
بالغــات خنفسـاء الحبـوب المنشــارية. حيـث كانــت جميـع المستخلصـات المدروسـة طـاردة عنـــ التركيزين 7\% 7\% 9\%، وكان نأثير ها ضـعيفاُ عند التر اكيز الدنيا من المستخلصـات،

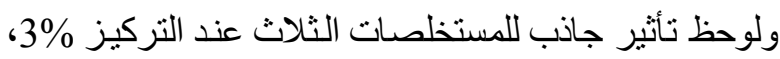
فكان مستخلص الأكاسيا ذا تأثنير جـانب للحشرة المدروسـة عند التركيز 3\% بعـد نصـف ســاعة مـن التعـريض، وكـان

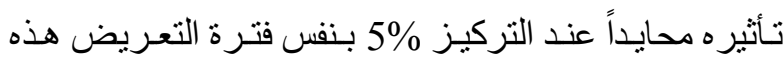
وبعـد سـاعتين مـن التعـريض، كمــالــوحظ تـأثير جـاذب لمسـتخلص الأوكـالييتوس بعد نصـف سـاعة وسـاعتين مـن

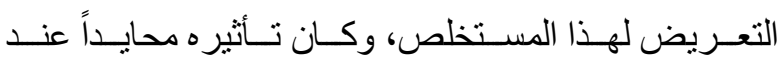
التركيـزين \% 3\% و 5\% بعـد 4 ســاعات مــن التعــريض. وتر اوحت قوة طرد هذين النباتين بين الفئات الثالثة و الر ابعـة

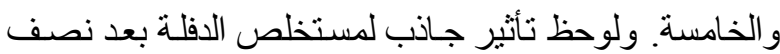
سـاعة وسـاعتين من التعريض لهذا المستخلص. وتر اوحت

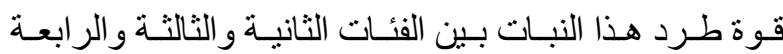

$$
\text { و الخامسة (الجدول رقم 3). }
$$

(حسب مدة الطـور اليرقي وهـي 3 أيسام وسـبياً) وحسـبت النسبة المئوية لموت الأطوار اليرقية الثلاث. • سجل منوسط عدد الحشرات الميتة بعد 1-4-710 أيام من المعاملة بالنسبة للبالغات في المكررات الثلاثتة، وحسبت أيضـاً النسبة المئويسة للموت وتم تصحيحها بمعادلة ن Abbott, 1925 نسبة الموت في المعاملة- نسبة الموت في الثاهد نسبة الموت في الشاهد ×100 تـم تحليـل النتـائج إحصـــائياً باسـتعمال البرنــامج الإحصائي IBM SPSS version 20، ونم اختبار معنوية المتوسطات باستعمال عامل بيرسون.

\section{3.}

1-2-3 التــأثير الطــارد للمستخلصــات النباتيـة المائيــة

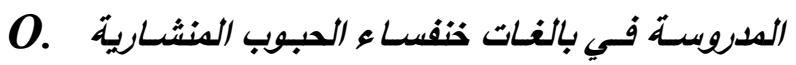
:surinamensis بينت النتائج أن للمستخلصـات الثناث تأثير اً طسارداً

في بالغـات خنفسـاء الحبوب المنشـارية O.surinamensis تفاوت هذا التأثير حسب تدرجات التر اكيز وحسب النبات

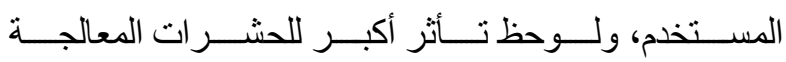
بالمستخلصـات مباشـرة بعد تعريضــها للمسـتخلص، وسـل عـدد أكبـر مــن الحشـرات فـي النصــف غيـر المعامـلـ

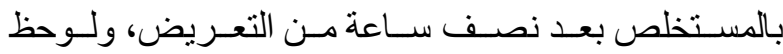
اضطر اب حركة الحشر ات في أطباق التجربـة بعد سـاعتين

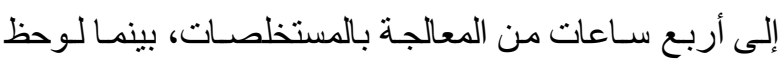
ثبـات نسـبي لعـد الحشـرات في الأنصـاف غيـر المعاملــة بالمستخلصات بعد 24 ساعة من التعريض. • أظهرت النتائج أن التر اكيز العليا من المستخلصـات

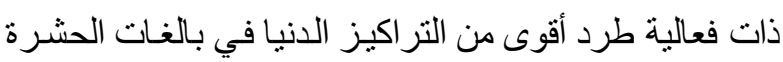
المدروسة، حيث حقق نبات الأكاسيا أعلى نسبة مئويـة للطرد

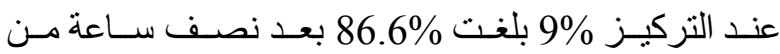




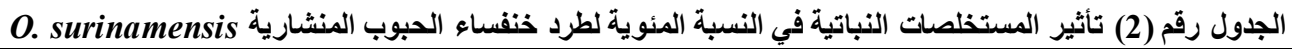

\begin{tabular}{|c|c|c|c|c|c|c|c|c|c|c|c|c|}
\hline \multirow{2}{*}{ للأل المئودية } & \multicolumn{2}{|c|}{ متوسط علد الحشر في } & \multirow{2}{*}{ للأطرد بعدية النسية } & \multicolumn{2}{|c|}{ متوسط عدات في } & \multirow{2}{*}{ للاطرد بائة النسبة 2 سابة } & \multicolumn{2}{|c|}{ متوسط عدات في } & \multirow{2}{*}{ للأل المردية النسية } & \multicolumn{2}{|c|}{ متوسط عدات في } & \multirow{2}{*}{ المستخلص النباتي } \\
\hline & المعاملة & الثشاهد & & |المعاملة & الثـاهد & & المعاملة & الثـار & & المعاملة & الشـاهد & \\
\hline $63.3 \%$ & 3.66 & 6.33 & $56.6 \%$ & 4.33 & 5.66 & $50 \%$ & 5 & 5 & $46.6 \%$ & 5.33 & 4.66 & $3 \%$ \\
\hline $86.6 \%$ & 1.33 & 8.66 & $56.6 \%$ & 4.33 & 5.66 & $56.6 \%$ & 4.33 & 5.66 & $50 \%$ & 5 & 5 & $5 \%$ \\
\hline $90 \%$ & 1 & 9 & $63.3 \%$ & 3.66 & 6.33 & $56.6 \%$ & 4.33 & 5.66 & $83.3 \%$ & 1.66 & 8.33 & $7 \%$ \\
\hline $93.3 \%$ & 0.66 & 9.33 & $83.3 \%$ & 1.66 & 8.33 & $73.3 \%$ & 2.66 & 7.33 & $86.6 \%$ & 1.33 & 8.66 & $9 \%$ \\
\hline $60 \%$ & 4 & 6 & $6.6 \%$ & 4.33 & 5.66 & $43.3 \%$ & 5.66 & 4.33 & $43.3 \%$ & 5.66 & 4.33 & 1 \\
\hline $63.3 \%$ & 3.66 & 6.33 & $66.6 \%$ & 3.33 & 6.66 & $56.6 \%$ & 4.33 & 5.66 & $53.3 \%$ & 4.66 & 5.33 & الأوكالييتوس0\% \\
\hline $66.6 \%$ & 3.33 & 6.66 & $73.3 \%$ & 2.66 & 7.33 & $56.6 \%$ & 4.33 & 5.66 & $63.3 \%$ & 3.66 & 6.33 & الأوكالييتوس 7\% \\
\hline $83.3 \%$ & 1.66 & 8.33 & $83.3 \%$ & 1.66 & 8.33 & $80 \%$ & 2 & 8 & $70 \%$ & 3 & 7 & الأوكالييتوس 9\% \\
\hline $63.3 \%$ & 66 & 6.33 & $53.3 \%$ & 4.66 & 5.33 & $46.6 \%$ & 5.33 & 4.66 & $36.3 \%$ & 6.33 & 3.66 & $3 \%$ \\
\hline $66.6 \%$ & 3.33 & 6.66 & $63.3 \%$ & 3.66 & 6.33 & $53.3 \%$ & 4.66 & 5.33 & $56.6 \%$ & 4.33 & 5.66 & فلة 5\% \\
\hline $66.6 \%$ & 3.33 & 6.66 & $66.6 \%$ & 3.33 & 6.66 & $63.3 \%$ & 3.66 & 6.33 & $76.6 \%$ & 2.33 & 7.66 & الدفلة \% \\
\hline $86.6 \%$ & 1.33 & 8.66 & $83.3 \%$ & 1.66 & 8.33 & $70 \%$ & 3 & 7 & $76.6 \%$ & 2.33 & 7.66 & 90 \\
\hline
\end{tabular}

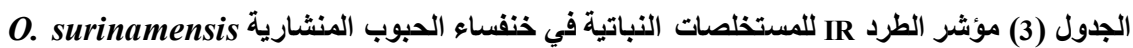

\begin{tabular}{|c|c|c|c|c|c|c|c|c|c|c|c|c|}
\hline الطرد & تقلقرد & | الطرد بدا & الطردة & تقزيبيم & الطرد بدر 4 سون & الطرد & تقلقرد & | الطرد بدر 2 بدا & الطردة & تقزيمد & الطرد بعد & النباتي وتركيزه \\
\hline 4 & طارد & 0.8 & 3 & طارد & 0.8 & 3 & محايد & 1 & 3 & جاذب & 1.06 & الأكاسيا 3\% \\
\hline 5 & طارد & 0.8 & 3 & طارد & 0.8 & 3 & طارد & 0.8 & 3 & محايد & 1 & الأكاسيا \\
\hline 5 & طارد & 0.7 & 4 & طارد & 0.7 & 3 & طارد & 0.8 & 5 & طارد & 0.3 & الأكاسيا \% 7\% \\
\hline 5 & طارد & 0.3 & 5 & طارد & 0.3 & 4 & طارد & 0.5 & 5 & طارد & 0.2 & الأكاسبا \% 9 \\
\hline 3 & طارد & 0.8 & 3 & محايد & 0.6 & 3 & جاذب & 1.13 & 3 & جاذب & 1.13 & الاوكالييتوس 3\% \\
\hline 4 & طارد & 0.7 & 4 & محايد & 0.6 & 3 & طارد & 0.8 & 3 & طارد & 0.9 & الأوكالييتوس \%\% \\
\hline 4 & طارد & 0.7 & 4 & طارد & 0.5 & 3 & طارد & 0.8 & 4 & طارد & 0.6 & الأوكالييتوس 7\% \\
\hline 5 & طارد & 0.3 & 5 & طارد & 0.3 & 4 & طارد & 0.4 & 4 & طارد & 0.6 & الأوكالييتوس \% 9 \\
\hline 4 & طارد & 0.7 & 3 & طارد & 0.9 & 3 & جانب & 1.06 & 2 & جاذب & 1.2 & الدفلة 3\% \\
\hline 4 & طارد & 0.6 & 4 & طارد & 0.7 & 3 & طارد & 0.8 & 3 & طارد & 0.8 & الدفلة 5\% \\
\hline 4 & طارد & 0.6 & 4 & طارد & 0.6 & 4 & طارد & 0.7 & 4 & طارد & 0.4 & الدفلة 7\% \\
\hline 5 & طارد & 0.2 & 5 & طارد & 0.3 & 4 & طارد & 0.6 & 4 & طارد & 0.4 & الدفلة \% 9 \\
\hline
\end{tabular}


في الثاهد إلى الطور الثالث، ولم تسجل أي حالة موت في يرقات الثاهد بعد فترة التعريض ذاتها (الجدول رقم 4).

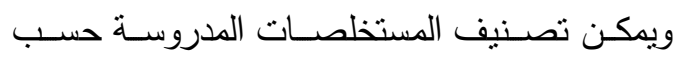
فعاليتها في قتل يرقات الطور الثاني من خنفسـاء الحبوب لُهاب المنشارية إلى: الدفلة> الأوكاليبتوس> الأكاسيا. الجدول رقم (4) التأثير القاتل للمستخلصات النباتية في يرقات الطور الإنيات

\begin{tabular}{|c|c|c|c|c|c|}
\hline \multicolumn{6}{|c|}{ O. Surinamensis الثاني من } \\
\hline \multirow{2}{*}{ لمتوسط عدد اليرقات } & \multirow{2}{*}{ 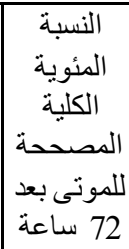 } & \multicolumn{3}{|c|}{ متوسط عدد اليرقات } & \\
\hline & & ساعة 72 & ساعة & ساعة & \\
\hline 10.35 & $\% 48.25$ & 3.66 & 3.66 & 2.33 & الأكاسيا 3\% \\
\hline 8.67 & $\% 56.65$ & 1.67 & 1.33 & 8.33 & الأكاسيا \\
\hline 7.44 & $\% 62.8$ & 0.33 & 3.66 & 8.66 & الأكاسيا 7\% \\
\hline 6.68 & $\% 66.6$ & 0.33 & 4.33 & 8.66 & الأكاسيا \% \\
\hline 7.67 & $\% 61.7$ & 2.33 & 4 & 6 & الاوكاليبتوس 3\% \\
\hline 6.67 & $\% 66.7$ & 3.33 & 4 & 6 & الأوكاليبتوس\% \\
\hline 3.35 & $\% 83.3$ & 3.66 & 6.66 & 6.33 & الأوكالييتوس 7\% \\
\hline 1.1 & $\% 94.5$ & 6 & 6.66 & 6.33 & الأوكالييتوس 9\% \\
\hline 6.01 & $\% 69.95$ & 4 & 4.66 & 5.33 & الدفلة 3\% \\
\hline 6 & $\% 70$ & 4. 33 & 4.33 & 5.33 & الدفلة \%5 \\
\hline 3.01 & $\% 84.95$ & 0.66 & 8 & 8.33 & الدفلة 7\% \\
\hline 0.35 & $\% 98.25$ & 6.66 & 6.66 & 6.33 & الدفلة \% 9 \\
\hline 20 & $0 \%$ & 0 & 0 & 0 & الثـاهد \\
\hline
\end{tabular}

3-2-2-2-2-2 التـأثير القاتـل للمستخلصـات النباتيـة في يرقات الطور الثالث: - ت

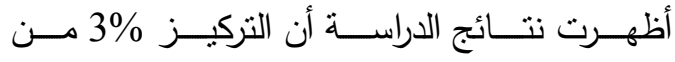
مستخلص الأكاسيا سبَب موت 38.25\% من برقات الطور

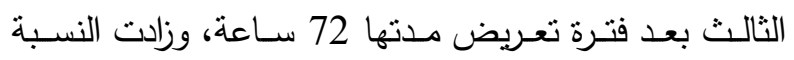

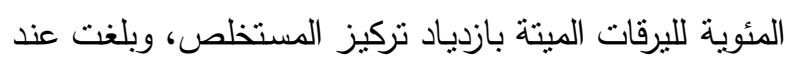
التركيزين 5\% و 7\% بعد فترة التعريض ذاتها 54.95\% و لإنئ
3-2-2-2- التـأثير القاتـل للمستخلصــات التباتيــة المائيـة المدروسـة في يرقات ويالغـات خنفسـاء الحبوب المنشـارية :O. surinamensis

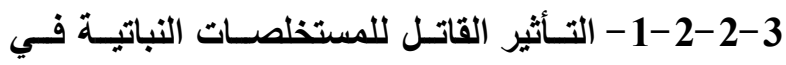

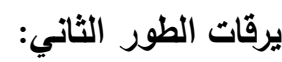

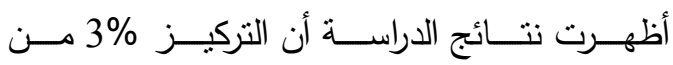
مستخلص الأكاسيا سبَب موت \% 48.25 من يرقات الطور

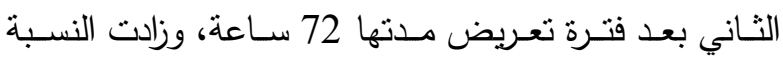
المئوية لليرقات الميتة بازدياد تركيز المستخلص، وبلغت عند

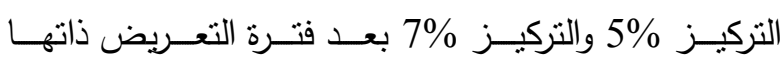
56.65\% و 62.8\% على التـوالي، وبلغـت أقصـى نسـبة

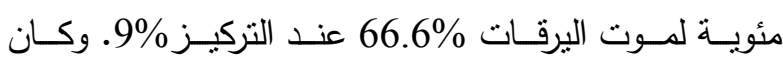
منوسط عدد يرقات الطور الثاني المتحولة إلى الطور الثالث 6.68 عند التركيز 9\% من مستخلص الأكاسيا.

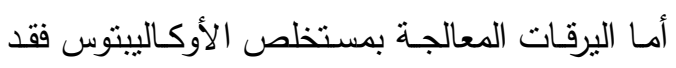
بلغت النسبة المئوية لليرقات الميتة 61.7\% عند أدنى تركيز 3\%، وازدادت هذه النسبة عند معاملة اليرقات بالتركيز 5\%

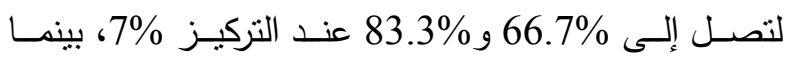

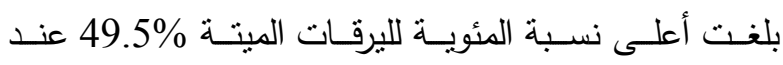
التركيـز 9\% بعـد فتـرة تعـريض مـدتها 72 سـاعة، وكــان منوسط عدد اليرقات المتحولة إلى الطور الثالث قليلاً مقارنـةً

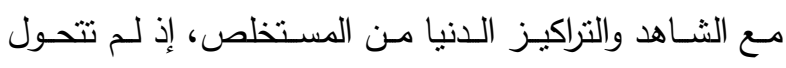
سوى 1.1 عند هذا التركيز من المستخلص.

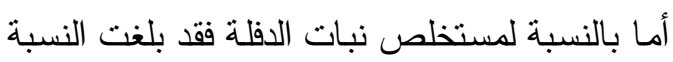

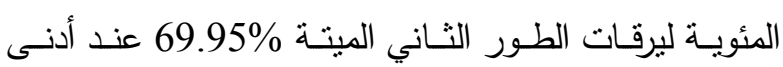

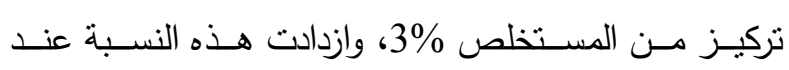

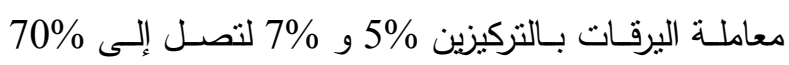
و 84.95\% على التوالي، وبلغت هذه النسبة 98.25\% عند معاملة اليرقات بـأعلى تركيز \% 9\% بعد فترة تعـريض مدتها

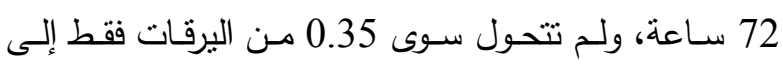

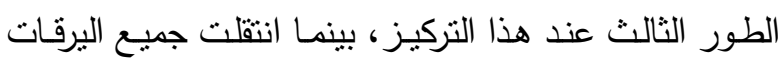


الجدول رقم (5) التأثير القاتل للمستخلصات النباتية في يرقات الطور

\section{O. الثالث من Surinamensis}

\begin{tabular}{|c|c|c|c|c|c|}
\hline \multirow{4}{*}{ 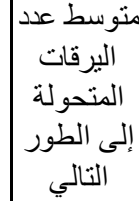 } & \multirow{4}{*}{ للموتل الكلية المئوية } & \multirow{2}{*}{\multicolumn{3}{|c|}{ متوسط عدد اليرقات }} & \multirow[t]{4}{*}{ /نسبة الموت } \\
\hline & & & & & \\
\hline & & \multirow{2}{*}{$\begin{aligned} 72 \\
\text { ياعة }\end{aligned}$} & \multirow{2}{*}{ س اعة } & \multirow{2}{*}{ س } & \\
\hline & & & & & \\
\hline 12.35 & $\% 38.25$ & 2.33 & 2.66 & 2.66 & الأكاسيا 3\% \\
\hline 9.01 & $\% 54.95$ & 1.33 & 1.33 & 8.33 & الأكاسيا 5\% \\
\hline 8.34 & $\% 58.3$ & 5 & 3.66 & 3 & الأكاسيا 7\% \\
\hline 7.01 & $\% 65$ & 0.33 & 4 & 8.66 & الأكاسيا \% 9 \\
\hline 11.34 & $\% 43.3$ & 0.66 & 2 & 6 & الأو كاليبتوس 3\% \\
\hline 10.68 & $\% 46.6$ & 0.66 & 2 & 6.66 & الأو كالييتوس\%5\% \\
\hline 10 & $\% 50$ & 1.67 & 5 & 3.33 & الأوكالييتوس \%\% \\
\hline 6.34 & $\% 68.3$ & 3.66 & 2 & 8 & الأوكالييتوس \% \\
\hline 7.67 & $\% 61.65$ & 6.33 & 1 & 5 & الدفلة \%3\% \\
\hline 7.01 & $\% 64.95$ & 0.66 & 4 & 8.33 & الدفلة 5\% \\
\hline 6.01 & \%69.95 & 1.66 & 4 & 8.33 & الدفلة 7\% \\
\hline 5.34 & $\% 73.3$ & 4.66 & 5 & 5 & الدفلة \% 9 \\
\hline 20 & $0 \%$ & 0 & 0 & 0 & الثشاهد \\
\hline
\end{tabular}

3-2-2-3-3-3 التـأثير القاتـل للمستخلصـات النباتيـة فـي

يرقات الطور الرابع:

أظهــرت نتــائج الدراســـة أن التركيـز 3\% 3\% مـــن

مسـتخلص الأكاسـيا سـبَب مـوت 23.3\% فقط مـن برقـات

الطـور الرابـع بعـد فتـرة تعـريض مـدتها 72 سـاعة، وزادت النسبة المئويـة لليرقات الميتـة عند التركيزين 5\% و 7\% بعد فتـرة التعـريض ذاتهـــا لتبـــغ \% 36.65\% و 46.7\% علـى التوالي. وبلغت أقصى نسبة مئوية لموت يرقات الطور الرابع 50\% عند التركيز \% 9. وكان متوسط عدد اليرقات المتحولة

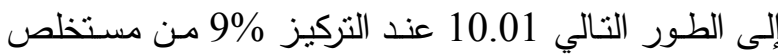
الأكاسيا بعد 72 ساعة من المعالجة.

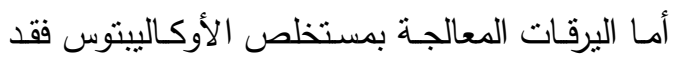
بلغت النسـبة المئويـة لليرقات الميتـة 26.7\% عنــ التركيـز 3\% و 30\% عند التركيـز 5\%، وازدادت هـذه النسـبة عند

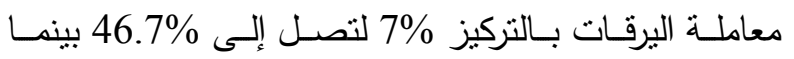

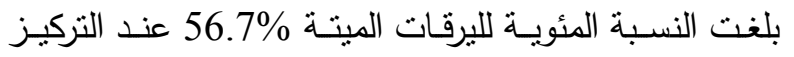
9\% بعد فترة تعريض مدتها 72 ساعة.
58.3\% على التـوالي. وبلغـت أقصـى نسـبة مئويـة لمـوت يرقات الطور الثالث 65\% عند التركيز 9\%، وكان منوسط عدد اليرقات المتحولة إلى الطور الرابع 7.01 عند التركيز 9\% من مستخلص الأكاسيا.

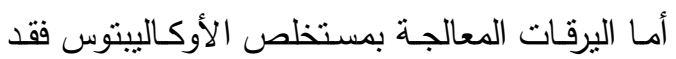

بلغت النسبة المئوية لليرقات الميتة \% 43.3\% عند أدنى تركيز 3\%، وبلغت هذه النسبة \% 46.6\% و 50\% على النوالي عند الند

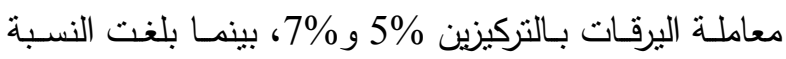

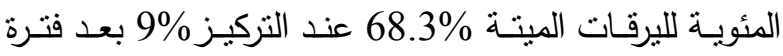

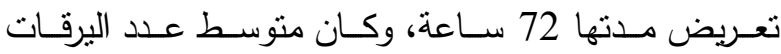

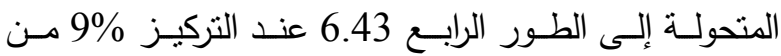

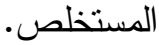

أما بالنسبة لمستخلص نبات الدفلة فقد بلغت النسبة

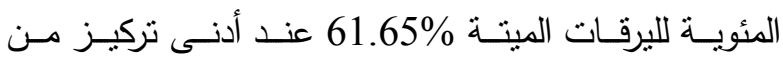
المستخلص 3\%، وازدادت هذه النسبة عند معاملـة اليرقـات

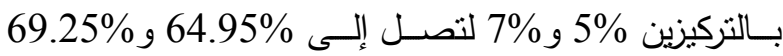

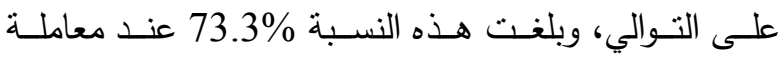

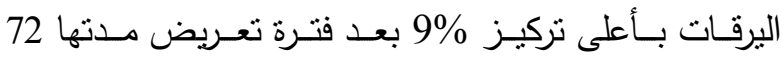

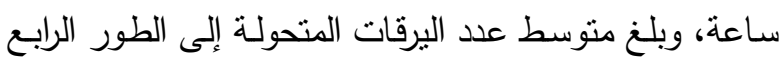

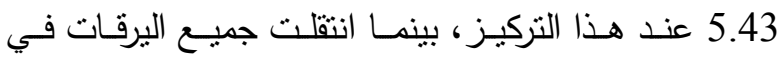

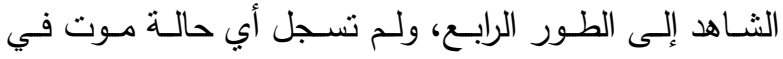
يرقات الثاهد بعد فترة التعريض ذاتها (الجدول رقم 5).

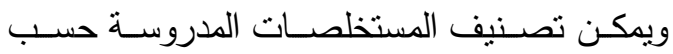
فعاليتها في قتل يرقات الطور الثالث من خنفسـاء الحبوب لهبات المنشارية إلى: الدفلة> الأوكاليبتوس الأكاسيا. 
الجدول رقم (6) التأثير القاتل للمستخلصات النباتية في يرقات الطور O. Surinamensis الر ابع من

\begin{tabular}{|c|c|c|c|c|c|c|}
\hline \multirow{2}{*}{ الطول فترة } & \multirow{2}{*}{ لمت اليرقات } & \multirow{2}{*}{ للمبلة الكلية } & \multicolumn{3}{|c|}{ متوسط عدد اليرقات } & \multirow[t]{2}{*}{ / نسبة الموت } \\
\hline & & & ساعة 72 & \begin{tabular}{|c|}
48 \\
ساعة
\end{tabular} & \begin{tabular}{|l}
24 \\
ساعة
\end{tabular} & \\
\hline 72 ساعة & 15.34 & $23.3 \%$ & 1 & 0.667 & 3 & الأكاسيا 3\% \\
\hline ا 72 ساعة & 12.68 & $36.6 \%$ & 2.33 & 2.33 & 2.66 & الأكاسيا \\
\hline ا 72 ساعة & 10.67 & $46.7 \%$ & 2 & 2.33 & 5 & الأكاسيا 7\% \\
\hline 96 ساعة & 10.01 & $50 \%$ & 2 & 4.66 & 3.33 & الأكاس \\
\hline 72 ساعة & 15.34 & $26.7 \%$ & 0 & 0.67 & 4.67 & الأوكالييتوس \%3 \\
\hline 72 ساعة & 14.01 & $30 \%$ & 1.66 & 2.33 & 2 & الأوكالييتوس0\% \\
\hline (96 ساعة & 10.67 & $46.7 \%$ & 1.33 & 3.33 & 4.67 & الأوكالييتوس \%\% \\
\hline 96 ساعة & 8.67 & $56.7 \%$ & 3.33 & 3 & 5 & الأوكالييتوس \% \\
\hline 72 ساعة & 9.34 & $53.3 \%$ & 2 & 5 & 3.66 & الدفلة 3\% \\
\hline | 72 ساعة & 8.68 & $56.6 \%$ & 1.66 & 2.33 & 7.33 & الدفلة 5\% \\
\hline (96 ساعة & 6.35 & $68.25 \%$ & 1.66 & 2.33 & 9.66 & الدفلة 7\% \\
\hline 96 ساعة & 6.01 & $69.95 \%$ & 8.66 & 3 & 2.33 & الدفلة \% 9 \\
\hline (272 ساعة & 20 & $0 \%$ & 0 & 0 & 0 & الثشاهد \\
\hline
\end{tabular}

3-2-2-3-2-3 التأثير القاتل للمستخلصـات النباتيـة المائيـة المدروسة في بالغات خنفساء الحبوب المنشارية: بينت النتائج أن للمستخلصات فياء الثناثلاث تأثيراً قاتلاً في خنفسـاء الحبـوب المنشـارية، ويختلف هذا التأثثر مـن مستخلص نبات لآخر ويتقاوت حسب تدرجات التراكيز وزمن التعريض وحسب المرحلة العمريـة. ومن أجل دراسـة التأثير

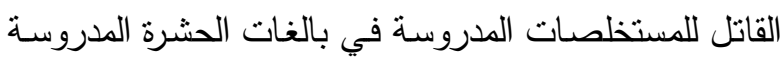

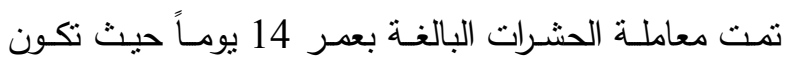

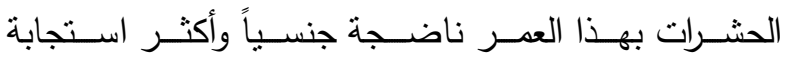
للمؤثرات، ونت تحديد فترة تعريض مدتها 12 يوماً نظراً لطول

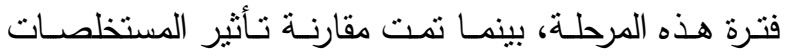

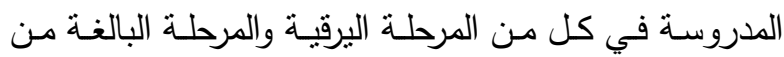
الحشرة خلال فترة تعريض مدتها 72 ساعة.
وكـان منتوســ عـد اليرقـات المتحولـة إلـى الطـور التالي 8.67\% عند التركيز $9 \%$ مـن المسـتخلص بعد 72

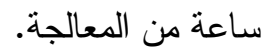

أمـا اليرقـات المعالجـة بمسـتخلص الدفلـة فقد بلغت النسبة المئويـة لليرقات الميتة 53.3.3 عند أدنى نركيز من المستخلص 3\%، وازدادت هذه النسبة عند معاملـة اليرقـات

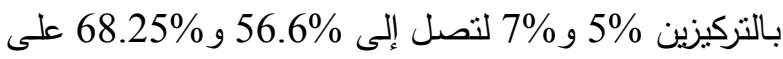
التوالي، وبلغت هذه النسبة 69.95\% عند معاملـة اليرقـات بأعلى تركيز 9\% بعد فترة تعريض مدنها 72 ساعة، وكان

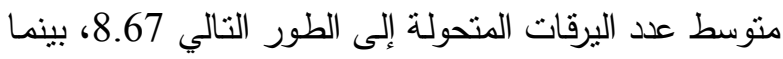
انتقلت جميـع اليرقـات في الثـاهد إلى الطـور التـالي، ولـم

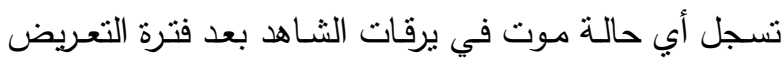
ذاتها.

ولوحظ إطالـة فترة الطـور الرابـع لليرقـات المعالجـة

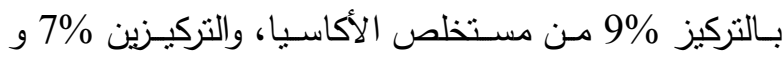

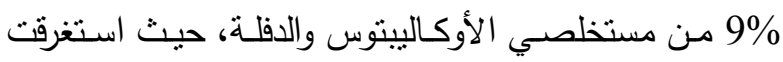

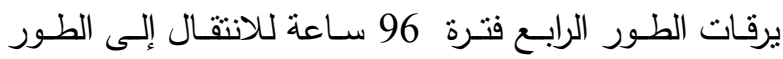

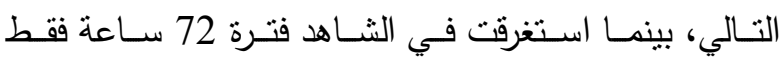

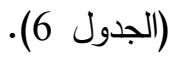

ويمكن تصـنيف المستخلصــات المدروسـة حسـبـ فعاليتها في قتل يرقات الطـور الرابع من خنفسـاء الحبوب المنشارية إلى: الدفلة>الأوكاليبتوس الأكاسيا. 
الجدول (7) التأثير القاتل للمستخلصات النباتية في بالغات خنفساء

O. surinamensis الحبوب المنشارية

\begin{tabular}{|c|c|c|c|c|c|c|c|c|c|}
\hline المئوية & النسبة & المئوية & & ميتة خذ & ات الم & الحشّر & ال عدد & منو سط & 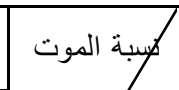 \\
\hline للمونى 12بعد & للموتى & للموت & 12 & 8 & 4 & 3 & 2 & 1 & \\
\hline $35.05 \%$ & $50 \%$ & $13.33 \%$ & 3.33 & 2.67 & 1.33 & 1.33 & 0.67 & 0.67 & الأكاسيا 3\% \\
\hline $51.75 \%$ & $66.67 \%$ & $16.67 \%$ & 4 & 3.33 & 2.66 & 1.667 & 1 & 0.667 & الأكاسيا:5\% \\
\hline $63.40 \%$ & $78.3 \%$ & $20 \%$ & 5 & 3.33 & 3.33 & 2 & 0.67 & 1.33 & الأكاسيا 7\% \\
\hline $70.11 \%$ & $85 \%$ & $21.7 \%$ & 5 & 3.67 & 4 & 0.67 & 1.67 & 2 & الأكاسيا 9\% \\
\hline $51.68 \%$ & $66.6 \%$ & $18.3 \%$ & 4 & 3.67 & 2 & 2 & 0.33 & 1.33 & الأوكاليبتوس \% \\
\hline $61.79 \%$ & $76.7 \%$ & $18.3 \%$ & 5 & 3.67 & 3 & 1.67 & 1 & 1 & الأوكاليبتوس0\% \\
\hline $73.46 \%$ & $88.35 \%$ & $23.3 \%$ & 5.33 & 3.67 & 4 & 2.67 & 0.67 & 1.33 & الأوكاليبتوس7\% \\
\hline $75.11 \%$ & $90 \%$ & $23.3 \%$ & 5.33 & 3.67 & 4.33 & 1.67 & 2 & 1 & الأوكالييتوس \% \\
\hline $65.10 \%$ & $80 \%$ & $15 \%$ & 5 & 5.33 & 2.67 & 0.33 & 1.67 & 1 & الدفلة \% \\
\hline $76.79 \%$ & $91.67 \%$ & $20 \%$ & 5 & 4 & 5.33 & 1.67 & 1.33 & 1 & الدفلة\% \\
\hline $78.45 \%$ & $93.33 \%$ & $23.33 \%$ & 5.33 & 4.33 & 4.33 & 2.33 & 1 & 1.33 & الدفلة 7\% \\
\hline $80.12 \%$ & $95 \%$ & $26.66 \%$ & 5.33 & 3.67 & 74.67 & 1.67 & 1.67 & 2 & الدفلة 9\% \\
\hline $0 \%$ & $15 \%$ & $0 \%$ & 0 & 3 & 0 & 0 & 0 & 0 & الشـاهد \\
\hline
\end{tabular}

r-r - r - مقارنــة التـأثير القاتـل للمستخلصــات النباتيــة المائيـة المدروسـة في يرقـات ويالغـات خنفسـاء الحبـوب المنشارية:

تمت مقارنة تأثير المستخلصات المدروسة في كل من المرحلـة البرقية والمرحلـة البالغـة مـن الحشرة خـلادل فتـرة

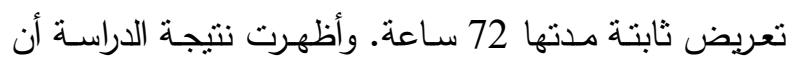
فعالية المستخلصـات النباتية بمختلف التراكيز كانت ضعيفة نسبياً في بالغات الحشرة وخصوصاً عند التراكيز المنخفضـة مقارنةً مـع فعاليتها في اليرقات، وقد ازدادت النسبة المئويـة

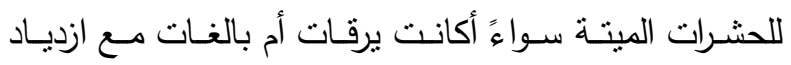
تركيز المستخلصـات حتى التركيز 9\% الذي أدى إلى موت

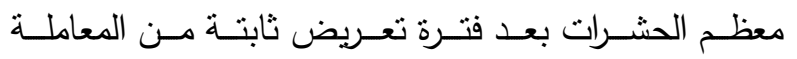
بالمستخلصات.
أظهـرت نتائج الدراسـة مـوت بعض البالغـات في الشاهد بنسبة مئوية لا تتجـاوز 15\% بعد 12 يوماً من بدء

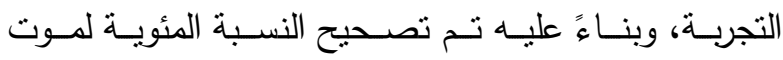

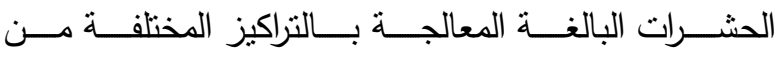
المستخلصات الثناث. سبَب التركيز 3\% من مستخلص الأكاسيا مـوت

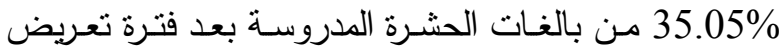

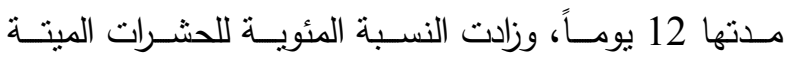
بازدياد نركيز المستخلص، وبلغت عند التركيز 5\% والتركيز

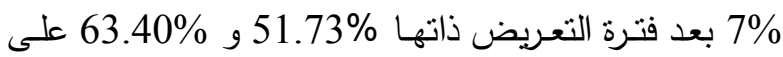
التوالي. وبلغت أقصى نسبة مئوية مصححة لموت البالغات عند التركيز \% 9 من مستخلص الأكاسيا 70.11\% بعد 12

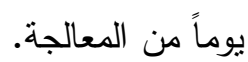
كما سبَب التركيز 3\% من مستخلص الأوكالييتوس

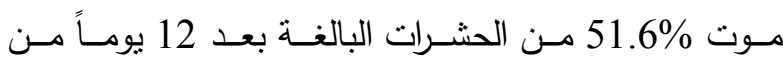
المعاملة، وبلغت النسبة المئويـة المصححة للحشـرات الميتـة

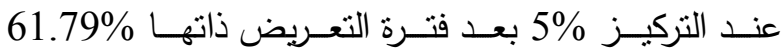
وازدادت هـذه النسـبـة عنـــ معاملـة البالغـات بـالتركيز

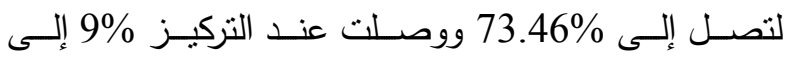
75.11\%بعد 12 يوماً من المعاملة بالمستخلص.

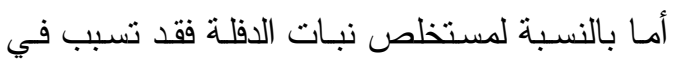
قتل بالغات الحشرة بنسبة بلغت 65.10\% عند أدنى نركيز مـن المسـتخلص 3\%، وازدادت هذه النسـبة إلىى \%

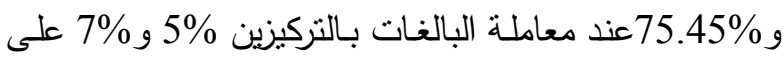

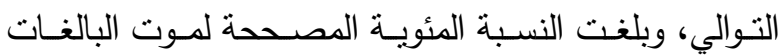
80.12\% عند المعاملة بأعلى تركيز \% 9 بعد 12 يوماً من

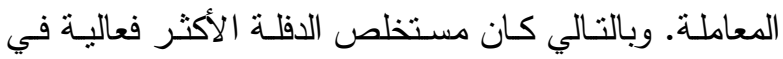

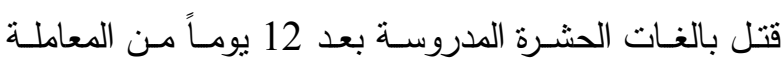
(الجدول رقم 7).

ويمكن تصـنيف المستخلصــات المدروسـة حسـبـ فعاليتها في قتـل بالغـات خنفسـاء الحبـوب المنشـارية إلىى: الدفلة> الأوكالييتوس> الأكاسيا. 
الجدول رقم (8) التأثير القاتل للمستخلصات النباتية في الأطوار اليرقية

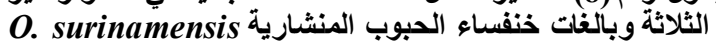

\begin{tabular}{|c|c|c|c|c|}
\hline \multicolumn{4}{|c|}{ |النسبة المئوية الكلية المصححة للموت بعد 72 ساعة } & \\
\hline بالغات & الطور الر ابع & الطور الثالث & |الطور الثاني & \\
\hline $13.33 \%$ & $23.3 \%$ & $38.25 \%$ & $48.25 \%$ & الأكاسيا 3\% \\
\hline $16.67 \%$ & $36.6 \%$ & $54.95 \%$ & $56.65 \%$ & الأكاسيا 5\% 5\% \\
\hline $20 \%$ & $46.7 \%$ & $58.3 \%$ & $62.8 \%$ & الأكاسيا 7\% \\
\hline $21.7 \%$ & $50 \%$ & $65 \%$ & $66.6 \%$ & الأكاسيا 9\% \\
\hline $18.3 \%$ & $26.7 \%$ & $43.3 \%$ & $61.7 \%$ & الأوكالييتوس 3\% \\
\hline $18.3 \%$ & $30 \%$ & $46.6 \%$ & $66.7 \%$ & الأوكالييتوس\% \\
\hline $23.3 \%$ & $46.7 \%$ & $50 \%$ & $83.3 \%$ & الأوكالييتوس 7\% \\
\hline $23.3 \%$ & $56.7 \%$ & $68.3 \%$ & $94.5 \%$ & الأوكالييتوس \% \\
\hline $15 \%$ & $53.3 \%$ & $61.65 \%$ & $69.95 \%$ & الدفلة 3\% \\
\hline $20 \%$ & $56.6 \%$ & $64.95 \%$ & $70 \%$ & الدفلة 5\% \\
\hline $23.33 \%$ & $68.25 \%$ & $69.95 \%$ & $84.95 \%$ & الذفلة 7\% \\
\hline $26.66 \%$ & $69.95 \%$ & $73.3 \%$ & $98.25 \%$ & الدفلة \% 9 \\
\hline $0 \%$ & $0 \%$ & $0 \%$ & $0 \%$ & الثـاهد \\
\hline
\end{tabular}

3-2-3 - الدراسة الإحصائية:

تدل قيمة معامل الارتباط بيرسون السلبية على أن النهائ

هنالك علاقة ارتباط عكسية قوية بين مؤشر الطرد وتركيز

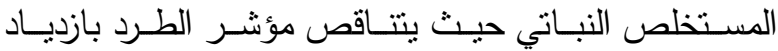

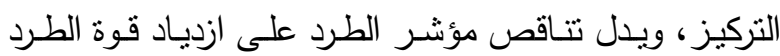

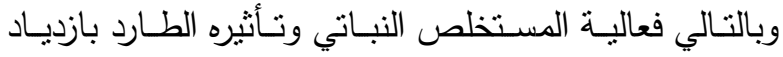

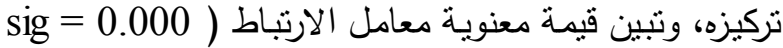

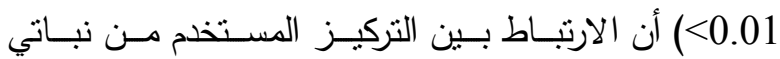

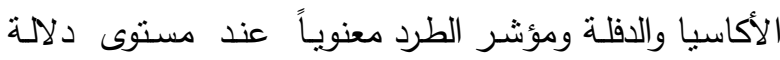

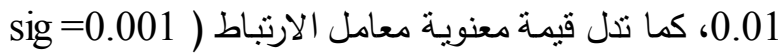

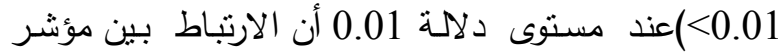

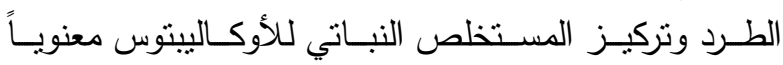

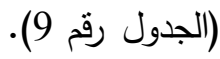

وكان مستخلص أوراق نبـات الدفلـة الأكثر فعاليـة في قتـل يرقات وبالغـات الحشرة المدروسـة، يليهه مسـتخلص الأوكاليبتوس ثم مستخلص الأكاسيا. وسبَب التركيز 3\% من مسـتخلص الأكاسـيا مـوت 13.33\% مـن بالغـات الحشـرة المدروسة بعد فترة تعريض مدتها 72 سـاعة، وزادت النسبة المئويـة للحشـرات الميتـة بازديـاد تركيز المسـتخلص، وبلغت عند التركيز $5 \%$ والتركيز $7 \%$ بعـد فتـرة التعـريض ذاتهـا 16.67\% 20\% على التوالي. وبلغت أقصى نسبة مئويـة لمـوت البالغـات 21.7\% عند التزكيز \% 9 بعد 72 سـاعة

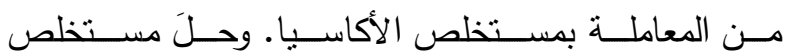
الأوكاليبتوس في دراستتا في المرتبة الثانية من حيث التأثير

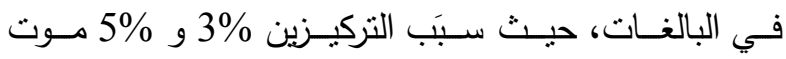
18.3\%من الحشـرات البالغـة بعد 72 سـاعة مـن المعاملـة، وبلغت النسبة المئويـة للحشـرات الميتـة عند التركيـزين و 9\% بعـد فتـرة التعـريض ذاتهــا 23.3\% بالمسـتخلص. وتسبَب مستخلص أوراق نبات الدفلة في قتل بالغات الحشرة بنسبة بلغت 15\% عند التركيز 3\% و بنسبة 20\% عند التركيز 5\% من المستخلص بعد فترة تعريض ثابتة مدتها 72 سـاعة، وازدادت هذه النسبة إلى مـ 23.33\% عند معاملـة

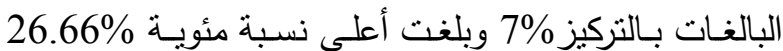
عند التركيز 9\% بعد 72 سـاعة من المعاملة بالمستخلص.

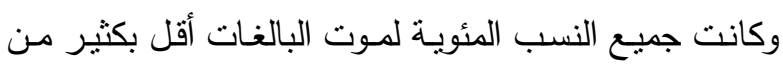
النسبة المئويـة لمـوت يرقـات الطـور الثاني والثالث والرابـع

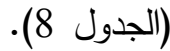


الارتبـاط بيرسـون **682-على أن هنـاك علاقـة ارتبـاط عكسية قوية بين الطور المعالج ونسبة الوفيات، وتبين قيمة الإنة

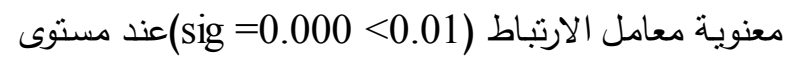
دلالة 0.01 أن الارتباط بين الطوثاطور المعالج ونسبة الوفيات

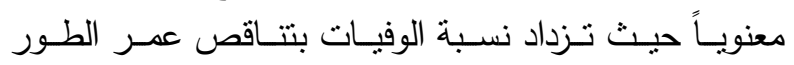
المعالج. (الجدول رقم 111). الجدول رقم (12) علاقة الارتباط بين نسبة الوفيات والتركيز والطور

\begin{tabular}{|c|c|c|}
\hline Correlation with mortality & concentration & stage \\
\hline Pearson Correlation & $.545^{* *}$ & $-.682^{* *}$ \\
\hline Sig. (2-tailed) & .000 & .000 \\
\hline
\end{tabular}

\section{4. المناقشة}

بينت النتائج أن للمستخلصـات النباتية الثنات تأثنيراً

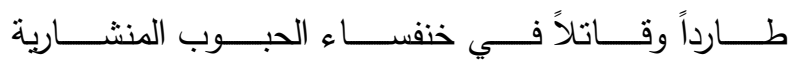
O.surinamensis نبات لآخر وحسب تدرجات التراكيز وزمن التعريض وحسب الطور المعالج، لوحظ من خلال التجارب تأثير طارد لنباتي الأكاسيا والأوكالييتوس أكبر من التأثير الطارد لنبات الدفلة فـي الحشـرة المدروســة حيـث تراوحـت قـوة الطـرد للنبـاتين السابقين بين الفئات الثالثة والرابعة والخامسـة، بينما نراوحت

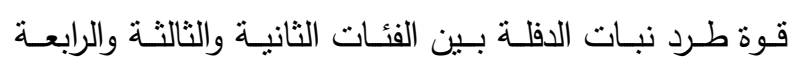
والخامسة. ويعود ذلك إلى اختلاف المكونـات الكيميائية لكل مستخلص[17]] فيما كان تأثير مستخلص نبات الدفلة في قتل فئل

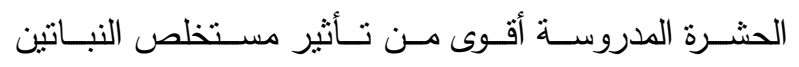

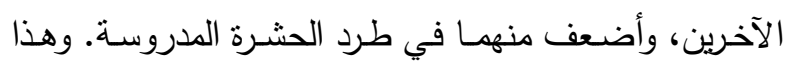

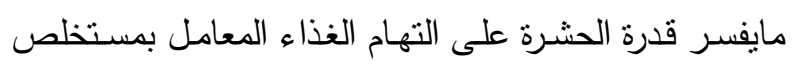

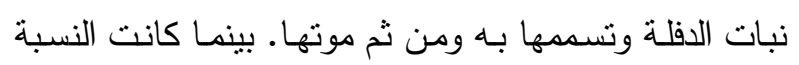
المئويــة لمـوت الحشـرات المعاملـة بمستخلصــي الأكاسـيا

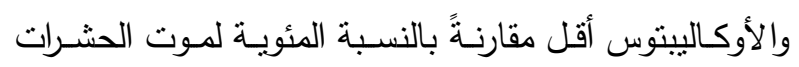

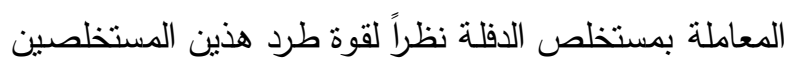

الجدول رقم (9) علاقة الارتباط بين مؤشر الطرد والتركيز والزمن حسب عامل بيرسون

\begin{tabular}{|c|c|c|c|}
\hline النبات & الارتباطمع مؤشر الطرد & التركيز & 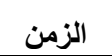 \\
\hline \multirow{2}{*}{ IR AC } & Pearson Correlation & $-.838^{* *}$ & $-.062-$ \\
\hline & Sig. (2-tailed) & .000 & .819 \\
\hline \multirow{2}{*}{ IR EU } & Pearson Correlation & $-.766^{* *}$ & $-.189-$ \\
\hline & Sig. (2-tailed) & .001 & .483 \\
\hline \multirow[t]{2}{*}{ IR NE } & Pearson Correlation & $-.840^{* *}$ & $-.318-$ \\
\hline & Sig. (2-tailed) & .000 & .230 \\
\hline
\end{tabular}
علاقة ارتباط طردية قوية بين النسبة المئوية للطرد وتركيز المستخلص النباتي حيث تزداد النسبة المئويـة للطرد بازدياد

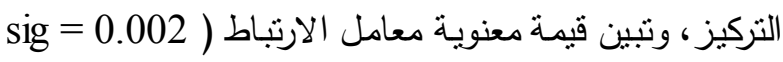

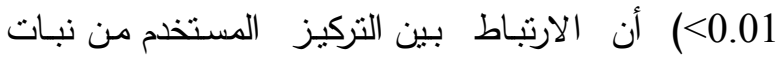

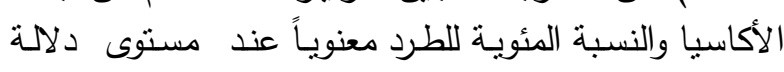

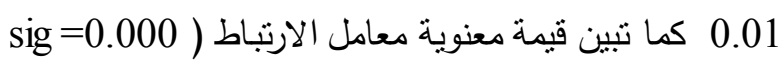

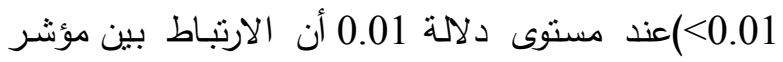

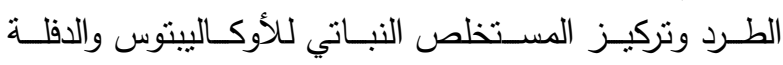
معنوياً (الجدول رقم 10).

الجدول رقم (10) علاقة الارتباط بين النسبة المئوية للطرد والتركيز والزمن حسب عامل بيرسون

\begin{tabular}{|c|c|c|c|}
\hline النبy| & النزي| \\
\hline \multirow{2}{*}{ PR AC } & Pearson Correlation & $.715^{* *}$ & $.534^{*}$ \\
\cline { 2 - 4 } & Sig. (2-tailed) & .002 & .033 \\
\hline \multirow{2}{*}{ PR EU } & Pearson Correlation & $.842^{* *}$ & .269 \\
\cline { 2 - 4 } & Sig. (2-tailed) & .000 & .313 \\
\hline \multirow{2}{*}{ PR NE } & Pearson Correlation & $.842^{* *}$ & .310 \\
\cline { 2 - 4 } & Sig. (2-tailed) & .000 & .242 \\
\hline
\end{tabular}
تدل قيمة معامل الارتباط بيرسون

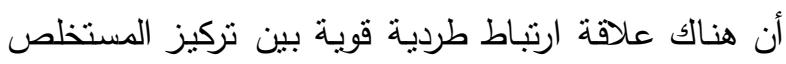

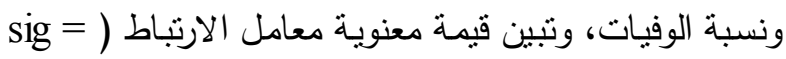

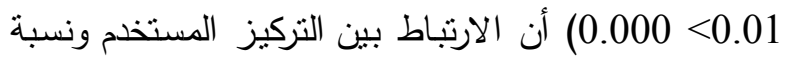
الوفيات معنوياً عند مستوى دلالة 0.00 0.01، كما ندل قيمة معامل 
وحـال دون وصـولها إلـى الطـور التـالي. وهذا مـاتوافق مـع

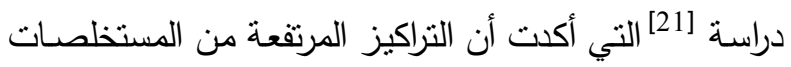
7.5\% و 10\% تحسث نسـبة عاليـة مـن المـوت لخنفسـاء

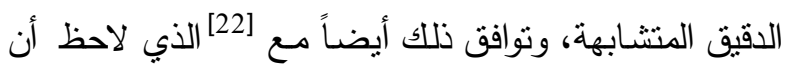
نسب القتل بتأثنير المركبات الفعالة في المستخلصات المائية

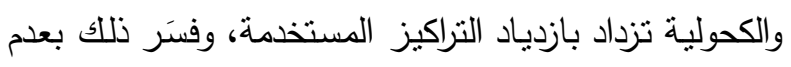
تمكن الحشرات من التخلص من المواد السامة بزيادة التركيز مما يؤدي إلى التسمم وحدوث خلل في النمو وزيادة نسب

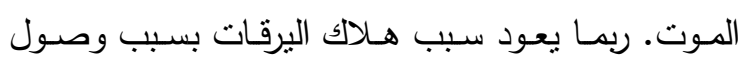

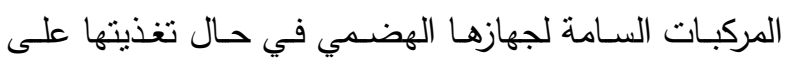
الحبوب المعالجة بالمستخلصـات، حيث تسبب المواد السـامة تلف الخلايـا الظهاريـة المبطنة للمعي المتوسط معرقلاً إفراز الإنزيمات الهاضمة وبالتالي موت اليرقات، أو أن المركبات

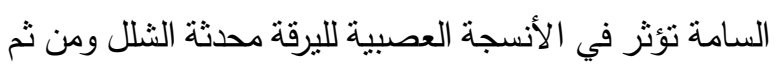

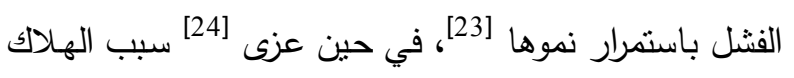

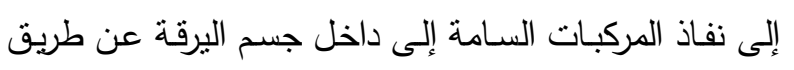
جدار الجسم أثناء أو بعد انسلاخها.

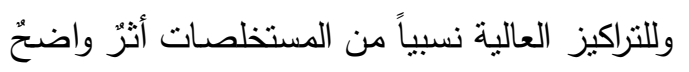

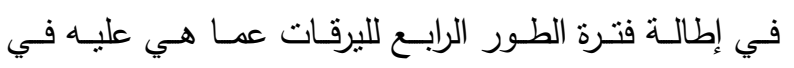
الثـاهد، حيث استغرقت اليرقات المعالجة بـالتركيز 9\% مـن مستخلص الأكاسيا والتركيزين 7\% و 9\% من مستخلصسي

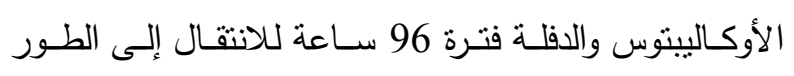
التالي، بينمـا استغرقت يرقات الطور الرابع في الثـاهد فترة

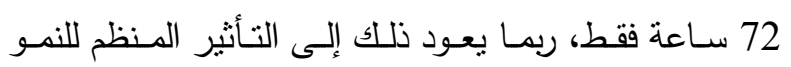

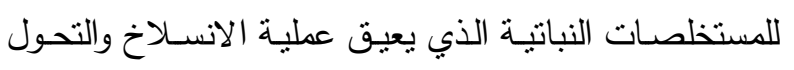

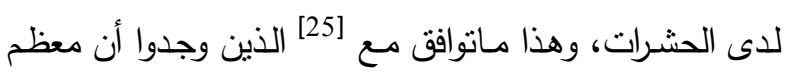

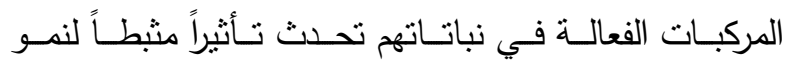
اليرقات، بينما كان منوسط فترة الطور اليرقي الثاني والثالث في جميع تراكيز المستخلصات النباتية المستخدمة منوافقاً مع لئع

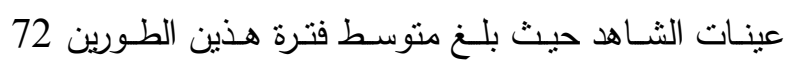
ساعة.
للحشــرة الهـدف وتجنــب الحثـرة التهــام الغـــاء المعامـلـ بالمستخلصــين ومــوت الحشـرات جوعـاً، ويعـود التبــاين الحاصل في النسبة المئويـة للجذب والطرد إلى التبـاين في

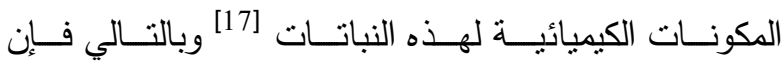
المستخلصات المضافة لغذاء الحشرة قد تؤثر في ردود الفعل

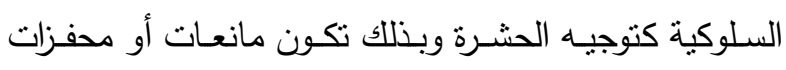

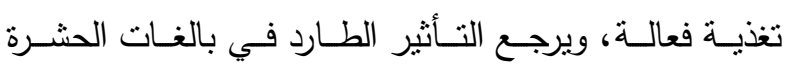
O.surinamensis زيـوت طيـارة ومـواد راتتجيـة وعفصـية تعهـل كمـواد طــاردة

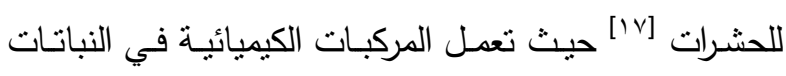

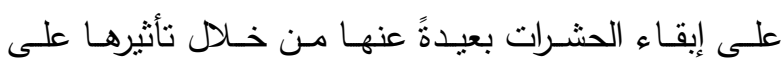

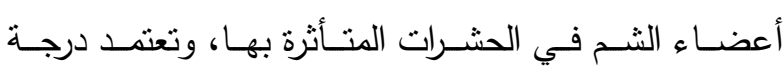

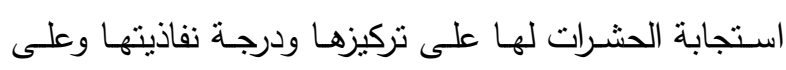

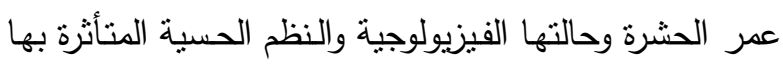
[18] ـــوحظ في دراسـتنا ازديـاد قوة الطـرد بازديـاد تركيـز

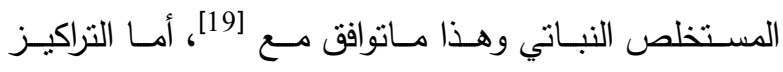
المنخفضــة نسـبياً فقـــ تسـبيت في جـذب الحشـرة، ويفسـر

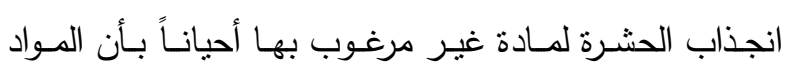
الفعالـة في المستخلصـات النباتيـة المختلطـة بمكونـات غذاء فئاء الحشرة قد لا تدرك من قبلها لأن تركيزها غير كافي وغير مؤثز في الاستجابة السمية للحشرة [20].

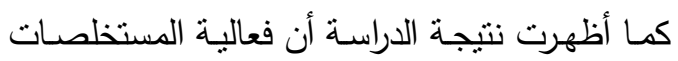
النباتية ذات التراكيز المنخفضة 3\% كانت ضعيفة نسبياً في

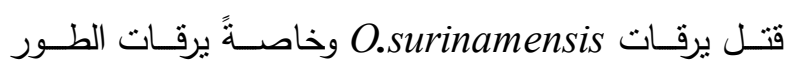

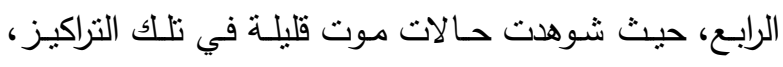

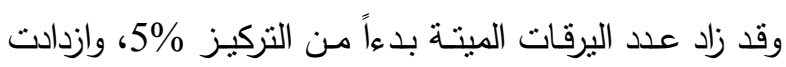
النسبة المئوية لليرقات الميتة مـع ازدياد تركيز المستخلصـات حتـى 9\% الـذي أدى إلـى مــوت معظـم اليرقـات بعـــ 72

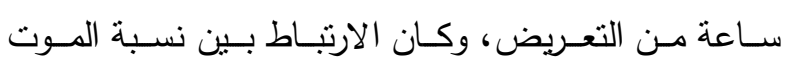
والتركيز معنويـاً. وبالتـالي سبب التركيز 9\% 9 مـوت النسـبة

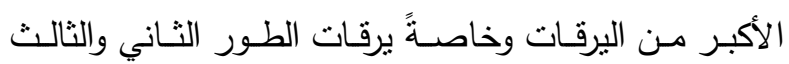


الفعالة للنباتات المدروسة [18]. حيث تفوق مستخلص أوراق

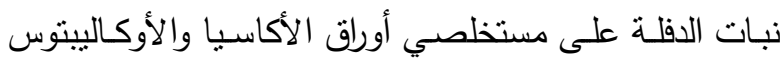
في قتل يرقات وبالغات خنفساء الحبوب المنشارية، وتوافقت

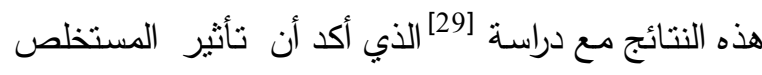

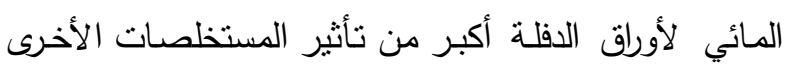
حسب التركيز المستخدم وزمن التعريض وعمر الحشـرة.

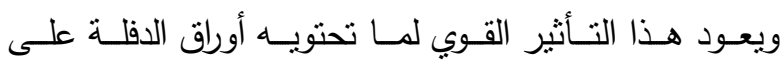
غليكوسـيدات سـامة مثل الأولنـدرين Oleandrin والنيـرين

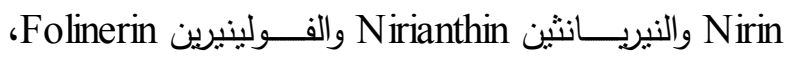
إضافة إلى الزيوت الطيارة والثمع وحمض العفص Tannic acid والمواد الراتتجية [17]. وحلَ مستخلص الأوكاليبتوس في دراستنا في المرتبـة الثانيـة

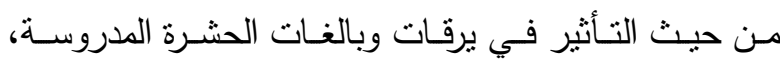
ويعود هذا التأثنر إلى ما تحتويه أوراق نبات الأوكالييتوس من ين ين زيوت ثابتة وطيارة تحتوي على مركب فينولي 1,8 cineole ومركب Eucalyptul الذي يمنلك خصـائص سـية قاتلـة،

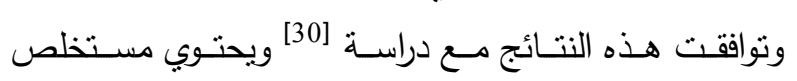

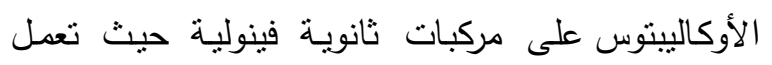
المركبات الفينولية على تغيير طبيعة البروتينات والإضرار

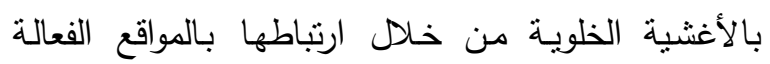
للأنزيمات الخلوية بواسطة مجاميع الهيدروكسيل فيها التي لها

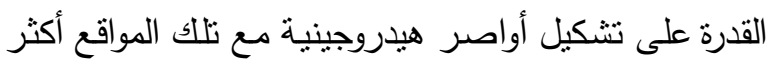
من المادة الأساس وبذللك فإنها تثبط واحد أو أكثر من التقاعلات الأيضية التي تسبطر عليها تلك الأنزيمات والتي قد

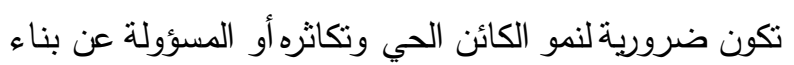

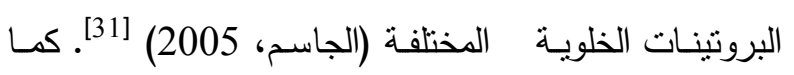
يحتوي على مركبات تربينية وأشباه الغليكوسيدات ومركبات فعالة طاردة للحشرات تعمل كمانعات تغذية وتؤدي إلى تثبيط عملية التغذي ووضع البيض ونسبة الفقس وتؤثر في عملية النمو وانسلاخ اليرقات [28].
وكانت يرقات الأطوار الفتية كالطور الثاني والثالث أشد تأثنراً بالمستخلصات من يرقات الطور الرابع والبالغات، وقد يكون السبب هو أن البالغات يكسو جسمها هيكل صلب يحميها من ين ئروات

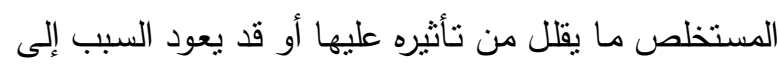

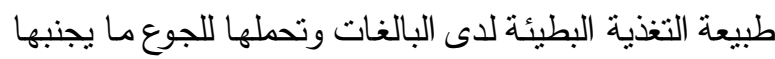
المستخلصات على عكس اليرقات التي تكون شرهة في تغذيتها وخصوصاً يرقات الأطوار الفتية التي تحتاج إلى كلى كميات كبيرة من الغذاء لغرض إكمال نموها، وتتقق هذه

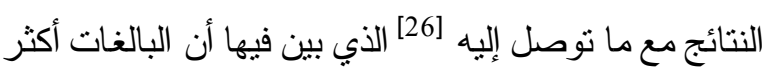
مقاومة للمستخلصات المائية لأوراق نبات الديدونيا، وتتفق

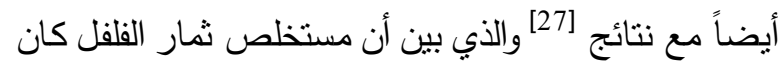
ذا تأثير أكبر على يرقات خنفساء الحبوب الكستتائية من

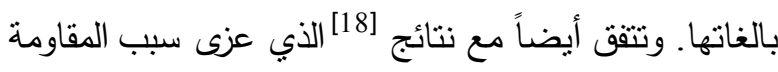
العالية التي أبدتها بالغات خنفسـاء الحبوب الكستتائية للمستخلص الكحولي للفلفل الحار مقارنة بيرقات الأطوار الفتية إلى أن الهيكل الصلب الذي يكسو جسم البالغات يشكل حماية لها من المستخلص الموجود في بيئنها مما يقلل من تأثنيره عليها وأيضاً إلى طبيعة التغذية البطيئة لدى البالغات،

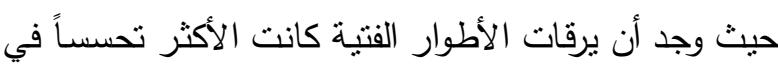
تجربته وحصلت فيها أعلى النسب للهالك التراكي مقارنة بيرقات الأطوار الأكبر والبالغات، واعتبر البالغات هي الأكثر

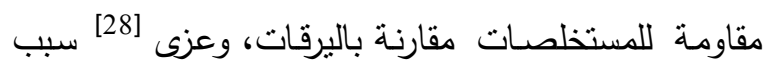
الهلاكات الحاصلة في بالغات الحشرات إلى تأثنر المركبات الكيماوية السامة الموجودة في المستخلص النباتي والتي نؤثر بشكل مباشر على الأعصاب مما يسبب شلالاً سريعاً للحشرات المعالجة به، أو قد يعود السبب إلى التأثثر السمي عن طريق لأني ملامسة المادة لسطح الجسم واختراق المركبات الكيميائية للمناطق المرنة في قشيرة الحشرة Cuticle أو عن طريق الفتحات التتفسية مسبية الثلل والموت السريع [28] وتباينت نسب الموت بين مستخلصات نباتات هذه الدراسة ويعود نلك إلى اختلاف المكونات الكيميائية والمادة 
للتراكيز العاليـة من المستخلصـات أثرُ واضحُ في إطالـة فترة الطور الرابـع لليرقات عمـا هي عليـه في الثـاهد ويعود ذلك إلى التأثنر المنظم للنمو للمستخلصات.

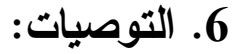

عزل وتتقية المواد الفعالة من أوراق نباتات الأكاسيا

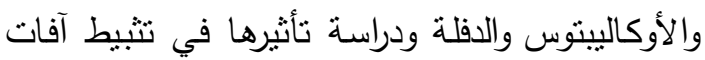

$$
\text { الحبوب المخزونة. }
$$

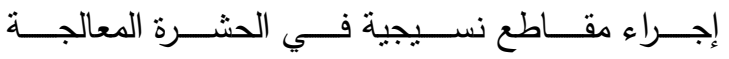
بالمستخلصات لتفسير سبب الموت ومعرفة آلية القتل. إجـراء دراسـة تطبيقيـة لإمكانيـة اسـتخدام المستخلصـات النباتية المدروسـة مـع المبيدات المعتمدة ضمن برامج المكافحة المتكاملة لهذه الآفة بهدف اختزال كميات المبيدات المستخدمة والحد من التلوث.

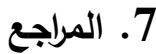

[1] الرهبان، بهاء، عدوان، شههاب، آفات الحبوب المخزونة في سـورية طرائق الوقاية والتعقيم، الهيئة العامـة للبحوث العلميـة والزراعيـة ومنظمـة الأمم المتحدة للتتمية، دمشق، 165 صفحة (2011).

[2] WHEELER Q D, Taxonomic triage and the poverty of phylogeny. Philosophical Transactions of the Royal Society of London, Series B-Biological Sciences, 359: 571-583 (2004).

[3] MASON L J, Grain Insect Fact Sheet: Sawtoothed Grain Beetle, Oryzaephilus surinamensis (L), Purdue University, Department of Entomology, 228 (2003).

[4] SORVARI J; HÄRKÖNEN S K; ESTERINEN $\mathbf{E} \mathbf{J}$, First record of an indoor pest sawtoothed grain beetle Oryzaephilus surinamensis (Coleoptera: Silvanidae) from wild outdoor wood ant nest. Entomologica Fennica, 23: 69-71(2012).

[5] LUCIA A; JUAN L.W; ZERBA E.N; HARRAND L; MARC M; MASUH H.M, Validation of models to estimate the fumigant and larvicidal activity of Eucalyptus essential oils against Aedes aegypti (Diptera: Culicidae). Parasitol. Res, 110 (5), 1675-1686 (2012).

[6] MOSTAFA M; HOSSAIN H; HOSSAIN M, BISWAS P.K; HAQUE M.Z, Insecticidal activity of plant extracts against T. castaneum Herbst. Journal of Advanced Scientific Research, 3 (3): 80-84 (2012).
وحلَ مستخلص الأكاسيا في دراستتا في المرتبـة الثالثة من حيث التأثثر في قتل اليرقات والبالغات. ويرجع تأثنير الزيوت القاتل للحشرة إلى إحداث صدمة عصبية للحشرة تشلها عن الحركة ومن ثم موتها [32]. ولــوحظ ازديـاد النسـبة المئويسـة لمـوت البالغــات المعالجـة بالمستخلصـات عند إطالـة فترة التعريض إلى 12

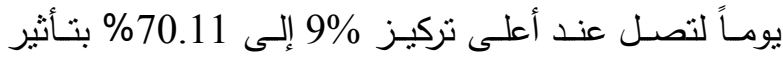

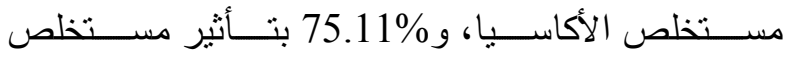

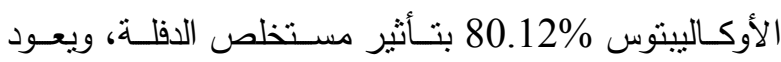

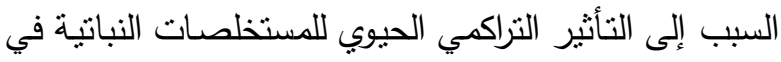

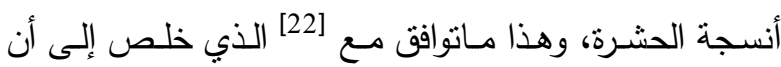
إطالة مدة المعاملة بالمستخلصات أدت إلى رفع نسب القتل

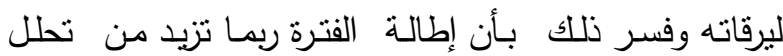
الخلايا الظهارية للقناة الهضمية للحشرة وبالتالي زيادة نسبة

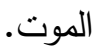

\section{5. الاستتتاجات}

لمستخلصـات أوراق نباتـات الأكاســيا والأوكــالييتوس الئس

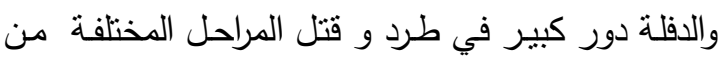
خنفساء الحبوب المنشارية O. surinamensis ضمن ورن الثـروط المخبريـة، ويعـود هـذا التـأثير الحيـوي لوجـود بعض المركبات الكيميائية السامة في تلك النباتات. للمستخلصـات النباتية المائية المدروسـة فعالية كبيرة في لائي

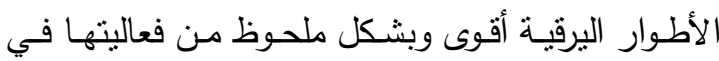
الحشرة البالغة، ويعود نلك إلى ضعف مقاومـة اليرقات التهات

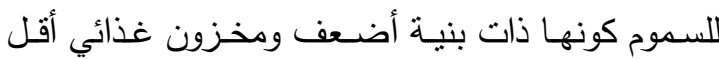
وشراهة أكبر للتغذية. كانت فعالية مستخلص الدفلة في قتنل يرقات وبالغات الحشرة المدروسة أقوى من فعالية مستخلصي النباتين الآخرين، ويفسر نلك باختلاف تركيب المواد الفعالة في كل مستخلص. 
[18] شعبان، عواد، والمـلاح، نزار مصطقى، المبيدات. دار الكتب للطباعة والنشر ، جامعة الموصل، 520 صفحة (1993).

[19] SAGHEER1 M; UL HASAN1 M; QURBAN ALI A.M; IQBALX SHAHID M; ALI K, repellent effect of four medicinal plant extracts to Trogoderma granarium EVERTS (Coleoptera: Dermestidae), J.Glob. Innov. Agric. Soc. Sci, 1(1): 9-11 (2013)

$$
\begin{aligned}
& \text { [20] روكسـتين، مسوريس، الكيمبـاء الحياتيـة للحشـرات (ترجمـة هـاني } \\
& \text { جهـاد العطـار ومحمـد فـرج الـسبد. دار الكتب للطباعـة والنشـر ، }
\end{aligned}
$$

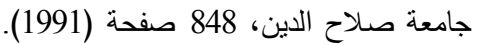

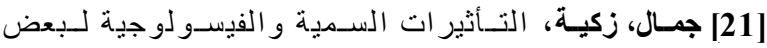

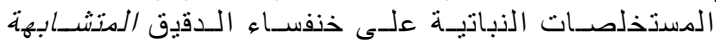

$$
\begin{aligned}
& \text { Tribolium } \\
& \text { confusum } \\
& \text { (Coleoptera:Tenebrionidae) }
\end{aligned}
$$

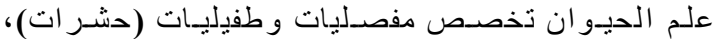

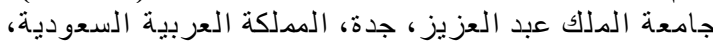

$$
\begin{aligned}
& 202 \text { صفحة (2008). } \\
& \text { [22] الظاهز، أريـج، حسن، سليم، تأثنير بعض المستخلصات النباتية } \\
& \text { في هلاك يرقات الطور الرابع وبالغات بعوض Culex pipiens } \\
& \text { molestus ، رسالة ماجستير ، قسم علوم الحياة، كلية العلوم، جامعة } \\
& \text { البصرة (2005). }
\end{aligned}
$$

[23] BOWERS W.S, Insect plant interactions: Endocrine defences. Pitman book, London. 188 pp (1984).

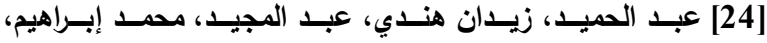

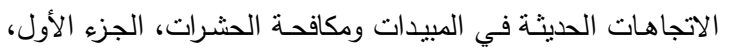

$$
\begin{aligned}
& \text { الافتصـاديات، الـار العربيـة للنشـر والتوزيـع، القـاهرة، } 572 \text { صـفحة }
\end{aligned}
$$

[25] PASCUAL VILLALOBOS M. J; ROBLEDO A, Screening for anti-insect activity in Mediterranean plants. Industrial Crops and Products, 8: 183-194 (1998).

$$
\text { [26] العارضي، جبار، عبادي، محمد، طه ثائر ، محمود، تأثنير مستخلص }
$$

الماء البارد والمغلي والكحولي لأوراق نبات Dodonaea viscoae

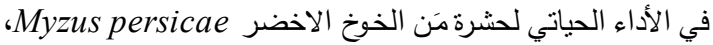

مجلة جامعة الكوفة لعلوم الحياة. المجلد1، العد1، ص -157

$$
\text { .(2002) } 162
$$

الأميز، هيا ،عبد عايد ساهرة الموسوي، محمود، ثائر الربيعي،[27]

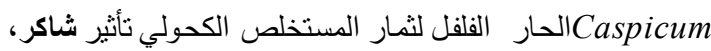
annuum L Lي هلاك يرقات وبالغات خنفسـاء الحبوب الحمراء castaneum Oryzaephilus
[7] MADDEN T.L; JOHANSEN M; FELIX E; NEWMAN R.A, Murine pharmacokinetics and metabolism of oleandrin, a cytotoxic component of Nerium oleander. J.Exp. Therap,Oncol, 2: 278- 285 (2002).

[8] DENNY E.F.K, Distillation of Eucalyptus leaf oils. p.161-180. In: "Eucalyptus: the Genus Eucalyptus, Medicinal and Aromatic Plants, Industrial Profiles",Vol22.(J.J.W.Coppen,ed.). Taylor \& Francis, London, 450 pp (2002).

[9] HALS TEAD D G H, Keys for the identification of beetles associated with stored products II. Laemophloediae, Passandridae and Silvanidae. Journal of Stored Product Research, 29: 99-197 (1993).

[10] THOMAS M C; WOODRUFF R E, A Stored Products Pest, Oryzaephilus acuminatus (Insecta:Coleoptera: Silvanidae), university of Florida, 188 (2007).

[11] MAMUN M. S. A; SHAHJAHAN M; AHMAD M., Laboratory evaluation of some indigenous plant extracts as toxicants against red flour beetle, T. castaneum Herbst. J. Bangladesh Agril. Univ, 7(1): 1-5 (2009).

[12] OBENG-OFORI D; REICHMUTH C.H; BEKELE A.J; HASSANALI A, Toxicity and protectant potential of camphor, amajor component of essential oil of Ocimum kilimandscharicum, against four stored product beetles. International Journal of Pest Management, 44: 203-209 (1998).

[13] MAZZONETTO F, Efeito de genótipos de feijoeiro e de pós origem vegetal sobre Zabrotes subfasciatus (Boh.) eAcanthoscelides obtectus (Say) (Coleoptera: Bruchidae). 134 pp.,Tesis Doctor en Ciencias. Universidad de Sao Paulo, Piracicaba,Sao Paulo, Brasil,134 pp (2002).

[14] TAPONDJOU AL; ALDER C; BOUDA H; FONTEM AD; REICHMUTH C, Bioactivities of cymol and essential oils of Cupressus sempervirens and Eucalyptus saligna against Sitophilus zeamais Motchulsky and Tribolium confusum du val. J. Stored Prod. Res., 41: 91-102 (2005).

[15] GULIANA G; SU HCF, laboratory studies on several plant material as insect repellents for protection of cereal grain. Journal of economic entromology, 76: 154-157 (1983).

[16] ABBOTT W.S, A method of computing the effectiveness of an insecticide. Journal of Economic Entomology,(18), 265-267 (1925).

[17] المنظمـة العربيـة للتنميـة الزراعيـة، النباتـات الطبيـة والعطريـة

والسامة في الوطن العربي، جامعة الدول العربية، الخرطوم، 477

صفحة (1998). 
لعلوم الكوفة جامعة ). مجلة Coleoptera:Tenebrionidae ).2010 (9-1ص: ، 2/العد ،/2لحباة، المجلد

[28] HALAWA Z.A; MOHAMED R; ELKASHLAN I.H, Laboratory Evaluation of some plants and insecticides against the beetle Callosobruchus maculates infesting stored product, Egypt. J. Agri. Res,76 (1): 85-93 (1998).

فرحان، شلال، أحمد عبد، طارق، محمد البيار، عز الدين، عطيه [129]

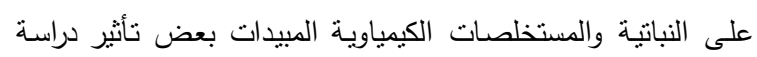
germanica

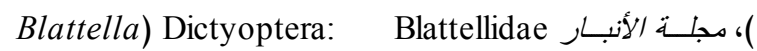
2010.) صفحات (8، 4 ، العلد 8/لزراعبة، المجلد

[30] MACIEL M.V; MORAIS S.M; BEVILAQUA C.M.L; SILVA R.A; BARROS R.S; SOUSA R.N; SOUSA L.C; BRITO E.S; SOUZANETO M.A, Chemical composition of Eucalyptus sp. essential oils and their insecticidal effects on Lutzomyia longipalpis. Veterinary Parasitology, 167: 1-7 (2010).

] محمد نوري جاسم، عبد القادر، دراسة بعض مكونات أوراق 31 ]

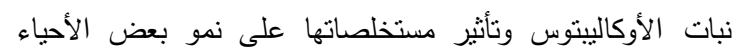

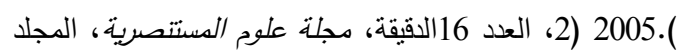

SEucalyptus camldulenis والدفبحج Nerium oleander والسبرل Melia

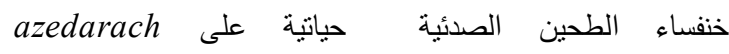

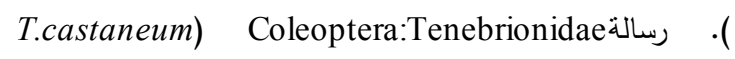
(2005:تكريت ( جامعة التربية، كلية ماجستير، 


\title{
Study of Lethal and Repellency effect of some plant extracts in Sawtoothed Grain Beetles Oryzaephilus surinam ensis Linnaeus, 1758 (Coleoptera: Silvanidae)
}

\author{
Razan khateeb , Mahmoud karrom, Mohmmad Ali Nakwan and Ahmed Al-lahem \\ Dept. of Animal Biology, Faculty of Sciences, University \\ of Aleppo, Syria
}

\begin{abstract}
:
The aim of the present study is testing the efficacy of water extracts of Acacia cyanophylla,Eucalyptus gomphocephala and Nerium oleander leaves to repel and kill larvae and adults of Sawtoothed Grain Beetles Oryzaephilus surinamensis. The difference in the percentage of dead insects according to the extract and concentrations, exposure time and stage was observed. The superiority of $N$. oleander extract to kill larvae and adults has appeared, followed by $E$. gomphocephala leaf extract, and then A. cyanophylla leaf extract. High concentrations of the three tested plants extracts achieved highest mortality in the larval stage and adult, and caused a relative increase in the longevity of the fourth instar larvae compared to the control. The study showed that the larvae of the second and third instar were more responsive to the lethal impact of extracts than the fourth instar larvae and adult insect.
\end{abstract}

Key words: plant extracts, the lethal impact, Repellency impact, larval stages, o.surinamensis. 